Testing for "contagion" of the subprime crisis on the Middle East and North African stock markets: A Markov Switching EGARCH approach

Wajif Khallouli, René Sandretto

Septembre 2010 


\section{GATE Groupe d'Analyse et de Théorie Économique Lyon-St Étienne}

93, chemin des Mouilles 69130 Ecully - France

Tel. +33(0)4 72866060

Fax $+33(0) 472866090$

6, rue Basse des Rives 42023 Saint-Etienne cedex 02 - France

Tel. +33 (0)4 77421960

Fax. $+33(0) 477421950$

Messagerie électronique / Email : gate@gate.cnrs.fr

Téléchargement / Download : http://www.gate.cnrs.fr - Publications / Working Papers 


\title{
Testing for "contagion" of the subprime crisis on the Middle East and North African stock markets: A Markov Switching EGARCH approach
}

\author{
Khallouli W. ${ }^{1}$, Sandretto R. ${ }^{2}$
}

\begin{abstract}
:
In this paper, we investigate whether the recent financial turmoil which arose in the United States has contaminated the Middle East and North African countries (MENA). In contrast to Lagoard-Segot and Lucey (2009), we try to identify the existence of pure contagion (Masson, 1999) rather than shift-contagion (Rigobon, 2003). Then, we explicitly define financial "contagion" in accordance with Eichengreen et al. (1996) and we extend the Cerra and Saxena (2002) methodology by using a Markov-Switching EGARCH model introduced by Henry (2009) in order to identify contaminated MENA stock markets. Our results provide evidence of a persistence of recession characterised by low mean/high variance regimes which coincides with the third phases of the subprime crisis. In addition, there is evidence of mean and volatility contagion in MENA stock markets caused by the US stock market.
\end{abstract}

JEL codes: C32, F31, G01, G15

Keywords: Subprime crisis, Contagion, MENA stock markets, Markov switching EGARCH model.

\section{Introduction}

Over the last two decades or so, the Middle East and North African (MENA) countries such as many emerging and developing countries have made significant progress toward trade and foreign exchange liberalization. To a lesser extent, some of them have moved toward a greater integration into the international financial system. Some countries, namely Lebanon, and Yemen, are already at an advanced stage of trade liberalization and capital account convertibility. Others, such as Egypt, and Jordan have made progress in eliminating import and exchange restrictions, lowering import tariffs and adopting current account convertibility. In recent years, the liberalization of inward capital movements has been pursued in most of these countries, together with a gradual relaxation of controls on outward capital flows. The reason for these policies was based on the general expectation that trade and financial liberalization would boost the economic activity by reinforcing competitiveness, opening new export markets, attracting foreign direct investment and stimulating savings and domestic investments. These reforms also paved the way for increased cooperation with developed countries, particularly with the European Union and the United States, leading sometimes to the conclusion of free trade agreements and even to association agreements. However, MENA countries still appear less integrated into international financial markets as compared to other

\footnotetext{
${ }^{1}$ Assistant Professor at ESSEC of Tunis (ESSECT), Wajih.khallouli@gmail.com

${ }^{2}$ Professor GATE, University of Lyon, rene.sandretto@univ-lyon2.fr
} 
emerging markets in Asia and South America. Many studies show that the MENA stock markets are not connected to developed financial markets (Yu and Hassan, 2006, LagoardeSegot and Lucy, 2007, Cheng et al., 2009).

However, nowadays there is no unanimous view about the consequences of this financial integration in emerging and developing countries. Some experts believe that financial liberalization produces unquestionably beneficial effects on growth and employment (Collins and Abrahamson, 2006), while others underline the fact that a wider integration into the international financial markets increases the vulnerability to foreign influences, particularly to reversals in international capital movements, which is generally referred to as the risk of "contagion". Therefore, these countries are becoming more and more vulnerable to negative foreign shocks (see: Colins and Biekpe, 2003; Bekaert and al., 2005). The subprime crisis, for example, was not actually confined to the US mortgage markets. As a result of securitization, the crisis spread to the entire financial market, not only in the US, but also to all developed countries (Horta et al. 2008). Within a couple of months, the Dow Jones index plummeted from 14,093 (September 28, 2007) to 12,980 (November 23, 2007) and then to 6,626 (March 6, 2009). Similarly, the CAC40 nosedived from 6,168 (June 1, 2007) to 5,442 (August 15, 2007) and to 2,519 (March 9, 2008). In addition, Dooley and Hutchison (2009) and Lahet (2009) find that many emerging markets were affected by the global financial crisis after a first phase of resistance until the Lehman Brothers bankruptcy in September 2008.

In any case, due to the current financial crisis, there is growing concern in MENA countries regarding the risk of contamination. Although these countries are less financially integrated because of capital controls, or due to a poor access to international financing ${ }^{3}$, they may be contaminated by contagion caused by the cognitive convergence of domestic investors during the global financial turmoil as suggested by Lagoarde-Segot and Lucey (2009). Indeed, domestic investors in a mid-sized market could become jittery and opt for the minimum cost strategy, selling their stocks when they observe high volatility in the US stock market (Alper and Yilmaz, 2004). Our objective, in this paper, is to investigate a possible financial "contagion" of the financial crisis originated in the US on the emerging markets of the MENA region. Given the limited openness of MENA stock markets, rather than focusing on the stock market crisis, we try to analyze if the switch to periods of high volatility in MENA equity returns could be statistically explained by events in the US equity market during the subprime crisis of 2007-2009. More particularly, we examine if "contagion" occurs into countries which have poorly liberalized their financial system, as it is the case for some of them in the region.

The rationale of this paper is based on the following statement: while an abundant literature has been devoted to the current financial crisis, only a few publications try to identify a possible transmission to emerging markets (see: Dooley M. and Hutchison M., 2009). Among them, the MENA region appears as the poor relation. This region is under-investigated despite the significant equity market development in the region since the 1990s (Table 1 in appendix 2). The paper of Lagoarde-Segot and Lucey (2009) can be considered as an exception. The authors tried to reduce this gap using the battery of shift-contagion tests based on the correlation approach. However, this framework requires a consistently high correlation between financial asset markets since it assumes the existence of interdependence according to the null hypothesis (Corsetti et al., 2005). In addition, in the MENA context, the interdependence with the US stock market seems unsubstantiated. In fact, using cointegration

\footnotetext{
${ }^{3}$ According to Lagoarde-Segot and Lucey (2007), MENA region is among the smallest attracting region of foreign investors (foreign capital represents $0.75 \%$ of GDP) compared with emerging countries.
} 
and causality tests, Neaim (2002), Soofi (2008) and Marashdeh and Shrestha (2010) show the absence of interdependence between MENA stock markets and developed stock markets and in particular the US stock market. Nevertheless, in this case, the correlation test is not the most appropriate for testing contagion. This analysis is too restrictive inasmuch as contagion and interdependence are mixed up. Obviously, there is no reason to assume that contagion can take place exclusively between strongly and permanently interdependent markets. In this paper, we refer to a more general concept in continuation of the approach suggested by Eichengreen et al. (1996). We define "contagion" as the increase in the probability of occurrence of a crisis in one country following the crisis in another country. Rather than shiftcontagion of Rigobon (2003), our definition coincides with pure contagion of Masson (1999) that does not require the existence of interdependence between the origin country (ground zero country) and the affected country.

In order to examine the contamination of MENA stock markets, following Chen $(2009,2010)$ and Henry (2009), we focus on the stock market evolution. Using a regime switching approach, we identify both bull and bear markets. The first is characterized by a high-mean?, low-variance regime and it corresponds to the no-crisis period while the second is characterized by a low-mean, high-variance regime and it corresponds to the crisis period. To investigate empirically the existence of contagion from the US stock market, we extend the Cerra and Saxena (2002) methodology using a time-varying transition probability (TVTP) Markov-switching EGARCH model introduced by Henry (2009). Given the fact that the correlation approach does not account for volatility as a potential factor of contagion (Baur, 2003), contrary to Lagoarde-Sego and Lucey (2009), we consider both mean contagion and volatility contagion following Baur (2003). The first is realised when changes in the US market returns ('ground zero country') affect the probability of switching between states (from bull market to the bear market) in one MENA stock market. Furthermore, we consider volatility contagion when the probability of switching from bull market to bear market in MENA stock market depends on the US stock market volatility ${ }^{4}$. This paper contributes to the literature in this field by investigating two important ways. Firstly, to our knowledge, this is the first time a Markov Switching approach has been used to identify contagion in MENA region during the subprime crisis. In contrast with the correlation approach, our methodology directly captures the individual stock market sentiment. However, the correlation approach is rather consistent with the structural change of links between markets which can be explained not only by shift in investor sentiment but also by endogenous liquidity shocks or political coordination (Forbes and Rigobon, 2001). The purpose of our paper is to investigate the effect of the subprime crisis on the MENA stock markets sentiment. In this sense, it seems to us that our paper complements the study of Lagoarde-Segot and Lucey (2009), inasmuch as it identifies pure contagion rather than shift contagion in the MENA stock markets. That is the main originality of our paper, since such an analysis has not been achieved up to this day. Secondly, the MS-EGARCH model is used for the first time in order to identify the contagion effect during the international financial crisis. Our model tries to capture persistence in the conditional variance and asymmetry in stock volatility within each regime (Henry, 2009) rather than the simple Markov switching model used by Cerra and Saxena (2002) in the stock market context.

The rest of the paper is organized as follows: section 2 presents different possible channels of transmission which can play a role in the case of emerging and developing countries.

\footnotetext{
${ }^{4}$ In this case, changes in volatility of the US market increase the volatility in MENA market during a particular period of time. That is the volatility contagion of Baur (2003).
} 
Section 3 describes the method that we use in order to identify "contagion". Section 4 presents the data and our findings. Section 5 gives some concluding remarks.

\section{Channels of "contagion"}

Before the 90's, the expression "contagion" was completely absent in the economic literature. It was only used in medicine, psychology and to a lesser extent in sociology and philosophy, with different meanings: transmission by direct or indirect contact; the spread of a behavior pattern, attitude, or emotion from person to person or group to group through suggestion, propaganda, rumor, or imitation; the tendency to spread, as of a doctrine, influence, or emotional state (the free dictionary).

Following the Asian crisis, it has become one of the most debated topics in international finance, with the meaning of correlation of market returns. However, there is no consensus about what "contagion" means. Actually, there are at least 5 possible significations of "contagion":

1. The most general and imprecise one regards "contagion" as the transmission of a crisis from one country to another (or from one market to another).

2. According to a second interpretation "contagion" occurs when the propagation of shocks is in excess of fundamentals, that is, when shocks have an different impact, more important, or faster than the regular transmission through the usual commercial or financial channels and mechanisms between countries or markets.

3. Another possible description is that "contagion" occurs when shocks spread as a result of panic movements and herding behavior of investors.

4. The fourth approach defines "contagion" as the transmission of shocks through any channel that causes markets to co-vary.

5. A fifth and more precise definition refers to "contagion" as a high frequency process of transmission of shocks which occurs with a higher probability during a crisis period than during normal or tranquil periods.

Not surprisingly, with such a variety of definitions, there is a great difference of opinions or conclusions about "contagion" frequency, even though these 5 definitions are not completely incompatible.

These different definitions raise several key questions: what are the channels through which crises spread across countries and markets? Are these channels specific to crises periods? In other words, are these crises contingent or not? Are these channels stable through time or do they change specifically during crisis periods?

With a more all-encompassing view, Forbes and Rigobon (2001) summarize these differences with a distinction between two kinds of approaches.

\subsection{Crisis non-contingent channels}

Crisis non-contingent channels of propagation are characterized by the fact that there is no difference in the transmission mechanisms between crisis and tranquillity periods. In both cases, shocks are propagated along the same causality lines through linkages between countries, which can be either structural (and permanent) such as trade links (Gerlach and Smets, 1995; Corsetti et al., 1999) and financial links (Kaminsky and Reinhart, 2000; Van Rijckeghem and Weder 2003) or temporary, such as common shocks (Masson, 1999); fundamentals-based "contagion" (Calvo and Reinhart, 1996; Kaminsky and Reinhart, 1999). More precisely, this fundamentals-based "contagion" can take three channels: 
Common shocks or monsoonal effect (Masson, 1999) are defined by simultaneous occurrence of crises in different countries which have similarities in macroeconomic policies and conditions. The contamination is caused by the incapacity of investors to discriminate between them after a common shock. According to Forbes and Rigobon (2001), the common shocks could be represented by random aggregate shocks (for example a rise in the international interest rate) or global shocks (for example a contraction in the international supply of capital).

Trade links are classified in two types of mechanisms: bilateral trade linkages and trade competition in third markets.

- The first one refers to a direct mechanism whereby a financial crisis in one country affects negatively other countries with high levels of bilateral trade. On the one hand, a financial crisis in the first country reduces import prices in the trading partners (Gerlack and Smet, 1995). Devaluation in the first country causes a drop in the export prices (denominated in foreign currency) of this country and consequently a reduction of the import prices in the trading partners. As a result, the trading partners suffer a negative price effect with a reduction of the consumer price index and a fall in demand for money and credit. Consequently, residents in these countries are prompted to convert domestic money into foreign currency, which causes the depletion of official reserves and may trigger a currency crisis (see: Reside Jr and Gochoco-Bautista, 1999). On the other hand, a financial crisis in the first country may turn into an economic crisis in this country. Consequently, the imports tend to decrease. This negative income effect spreads in the trading partners by reducing their exports and thus causing a trade deficit which sets up the domestic currency for a speculative attack (Hail and Pozo, 2008; Van Rijcheghem and Weder, 2001).

- The second type of mechanism suggests that financial crisis propagation can result from a loss of international competitiveness. In this case, depreciation or devaluation of the domestic money in the first country reinforces its competitiveness in the presence of nominal rigidities (Glick and Rose, 1999). This evolution negatively affects its main trading partners (with an important bilateral trade) or its main competitors that export to the same third markets. Consequently, the exports of these partners or competitors will decrease, creating a trade deficit which may contribute to the triggering of a crisis.

Financial links seem also to be an increasingly more important channel of "contagion" since emerging markets are increasingly integrated into global markets. Hence, with the global diversification of financial portfolios, the behavior of international investors are driven by two main factors. When a financial crisis occurs in one country, liquidity problems and information asymmetries can cause cross-border spillovers. These two factors also influence the behavior of international commercial banks which lend to several countries.

- If stock prices are tumbling down in one country, international investors may decide to sell off assets in other countries in order to rebalance their portfolios (Calvo, 1999). Valdes (1997) and Van Rijckeghem and Weder (2001) describe a similar mechanism at work when investors, upon receiving margin calls based on the decline in prices of some assets, decide to sell assets in other countries. Calvo (1999) underlines the fact that asymmetric information tends to amplify this portfolio rebalancing process. Logically, risk management techniques impose on investors the need to reduce their exposition in the most volatile and risky assets classes as well as credit lines in correlated markets. As a result, foreign banks will sell off loans and investments in other countries than the "ground zero" country, thereby spreading the crisis. 
- Obviously, a loss of liquidity is also an important spillover mechanism behind propagation, explaining why a crisis in a "ground zero" country (the first country to experience a crisis) tends to spread to other countries. Kaminsky and Reinhart (2000) and Van Rijckeghem and Weder (2001) also show that the behaviour of international commercial banks could cause cross-border spillovers. In case of a crisis in one country, the percentage of non-performing loans for foreign creditor banks will rise since the probability of repayment decreases. This leads to liquidity problems. Foreign banks then need to recapitalize and increase provisions for bad loans. Thus, they may withdraw their investments from other countries.

\subsection{Crisis contingent channels of propagation}

In this second approach, investors behave differently after a crisis in another country, implying as such the generation of new temporary channels of propagation and adding or substituting the permanent channels which are based on the various interdependences between the economies. It is sometimes described as "shift-contagion" and it can include three mechanisms: Endogenous liquidity shocks, political perception transmission and pure "contagion". The latter is generally the consequence of changes in investors' attitudes caused by financial panic and/or by the sudden perception of risks, leading to herding behaviors or switches of expectations (Masson 1999). Flavin et al (2008) distinguish between shiftcontagion and pure contagion. By contrast to shift-contagion, pure contagion is only active during periods of external stress and does not require the existence of normal levels of market interdependence. Therefore, for MENA countries, given their limited financial integration with developed countries, pure contagion due to switches of expectations of domestic investors seems more plausible than shift contagion.

For MENA countries, these two kinds of channels (non-crisis contingent channels vs. crisis contingent channels) can play a role, even though the first one seems more plausible, in as much as their financial markets are relatively small with a low volume of transaction and few listed companies, compared to developed markets (see table 2 in appendix 2). In this paper, we refer to Eichengreen et al. (1996), who consider "contagion" as the increase in the probability of crisis' occurrence in one country after the occurrence of a crisis in another country ("ground zero country"). This definition allows us to identify pure contagion as one of the crisis contingent channels (Forbes and Rigobon, 2001) from the US to MENA countries during the subprime financial crisis $2007-2009^{5}$. We focus our analysis on the stock market evolution. Therefore, identifying pure contagion is useful for both economic authority and international investors. Actually, bringing herding behaviours of domestic investors under control is a key aspect of MENA authorities (as well as in any other countries) in order to contain the financial crisis. In addition, given the sharp fall of equity markets in developed countries during the subprime crisis, testing for pure contagion can provide more information on the segmented MENA equity markets to investors, bankers and portfolio managers.

\footnotetext{
${ }^{5}$ Obviously, testing other forms of contagion is nonetheless useful for a thorough understanding of the mechanisms that can affect MENA countries. It will be a topic for future research.
} 


\section{Identifying “contagion" methodology}

How we can identify "contagion" ? Several different procedures, methodologies and techniques have been developed during the last 12 years. Most of them use the Probit/Logit methodology (Eichengreen et al. 1996; Glick and Rose, 1999; Caramazza et al. 2004). However, Cerra and Saxena (2002) used the Markov Switching approach to model the nonlinear behaviour of the crisis index without a need to transform it into a binary variable as it is the case in the qualitative models (probit or logit models) ${ }^{7}$. According to Abiad (2003), this transformation is based on the choice of a crisis index threshold which differentiates the tranquillity and crisis periods. Of course, such a preliminary choice is obviously arbitrary. Besides, it generates a loss of information with the possibility of uncaptured crises periods (Mariano et al. 2004). Following the above cited literature we apply the Markov Switching Regime Model (MSRM) to avoid these drawbacks.

By contrast to the currency crisis, in stock market context, the MSRM is not frequently used to identify contagion. To the best of the authors' knowledge, Cerra and Saxena (2002) are the only exceptions. In this study, we extend the Cerra and Saxena methodology using the MSEGARCH $(1,1)$ model introduced by Henry (2009). He modifies the EGARCH specification ${ }^{8}$ to account for such structural changes in the mean and variance terms using unobserved states $S_{t} \in\{0,1\}$. According to Chen (2009), $S_{t}=0$ indicates the low-mean, high-variance regime (bear market) and $S_{t}=1$ the high-mean, low-variance state (bull market). The $S_{t}$ process is assumed to follow a Markov chain of order one. Its transition probability matrix $P$ is given by:

$$
P=\left(\begin{array}{ll}
p_{00} & p_{01} \\
p_{10} & p_{11}
\end{array}\right)
$$

where ${ }^{p_{i j}}$ represents the probability ${ }^{9}$ that state ${ }^{j}$ at time $t-1$, will be followed by state $i$ at time $t$ :

$$
p_{i j}=\operatorname{Pr}\left(S_{t}=i / S_{t-1}=j\right) \forall i, j=0,1
$$

Therefore, the following equalities hold:

$$
\begin{aligned}
& p_{00}+p_{10}=1 \\
& p_{01}+p_{11}=1
\end{aligned}
$$

The MS-EGARCH model used in this paper is given by:

$$
\begin{gathered}
\psi(L) R_{t}=\mu_{S_{t}}+e_{t} \\
e_{t \sim} \operatorname{iidN}\left(0, h_{s_{t}}\right)
\end{gathered}
$$

\footnotetext{
${ }^{6}$ In order to clarify the terminology, we think that it would be better to use the word "contagion" " for pure form of "contagion" (as described originally by Masson, 1999), or for crisis-contingent mechanisms of contamination, or for crises based on herding behaviors of investors.

${ }^{7}$ Which are also used in the crisis EWS literature (e.g. Kamin et al. 2001).

${ }^{8}$ The linear EGARCH model was introduced by Nelson (1991) and proposed a positive conditional variance without need for non-negativity constraints as it is the case in the estimation of GARCH models.

${ }^{9}$ The transition probabilities, which are assumed to be constant over time, are specified by the logistic functional form (cf. Henry, 2009)
} 


$$
\log \left(h_{S_{t}}\right)=\omega_{S_{t}}+\alpha_{S_{t}}\left[\left|\frac{\varepsilon_{t-1}}{\sqrt{h_{t-1}}}\right|-\sqrt{2 / \pi}\right]+\beta_{S_{t}} \log \left(h_{s_{t-1}}\right)+\delta_{S_{t}} \frac{\varepsilon_{t-1}}{\sqrt{h_{t-1}}}
$$

where ' $R_{t}$, represents the return on one stock market index between time $t-1$ and $t, e_{t}$ is the error term for the return at time $t, \psi(L)$ is the lag operator and $\mu$ is the intercept term. Eq.(4) refers to the conditional mean in which intercept is allowed to switch between a high mean returns $\mu_{1}$ and a low mean returns $\mu_{0}$. In addition, Eq.(6) allows us to model the conditional variance of $R_{t}$ for a high volatility regime $h_{0}$ and the low volatility regime $h_{1}$. It ensures the positive conditional variance and account for the leverage effect ${ }^{10}$. That is coefficients $\delta_{0}$ and $\delta_{1}$ that allow capturing asymmetric respond of conditional variance to shock $\varepsilon_{t}$ of either sign for two regimes high/low volatility, respectively.

According to Cai (1994) and Hamilton and Susmel (1994), the autoregressive term $h_{t-1}$ in Eq.(6) leads to a path-dependent structure difficulty. In this case, maximum likelihood estimation of the model is computationally intractable because the conditional variance $h_{t}$ depends on the entire past history of unobserved regimes. Following Gray (1996) and Henry (2009), we adopt an approximation measure of $h_{t-1}$ in Eq.(6) to avoid the path dependent problem. Using the information observable at time $t-2$, the conditional expectation of the past variance is given by:

$$
\begin{aligned}
h_{t-1}=E_{t-2}\left\lfloor h_{S_{t-1}}\right\rfloor & p_{11}\left(\mu_{1, t-1}^{2}+h_{1, t-1}\right)+\left(1-p_{11}\right)\left(\mu_{0, t-1}^{2}+h_{0, t-1}\right) \\
& -\left[p_{11} \mu_{1, t-1}+\left(1-p_{11}\right) \mu_{0, t-1}\right]^{2}
\end{aligned}
$$

Using (7) in place of $h_{t-1}$ in Eq.(6), implies that each conditional variance is depending only on the most recent regime and not on the entire history of the process (Henry 2009).

The chief objective of this study is to identify the "contagion" effect of the US subprime crisis to the MENA stock markets. To this end, we first test the superiority of the Markov switching model with transition probabilities varying over time. Then, we go further by adopting timevarying transition probabilities (TVTP) depending on $z_{t}$ in the benchmarking MS-EGARCH model. In order to detect the US subprime crisis, we consider first the negative shocks of the US stock markets return when ${ }^{z_{t}}$ decreases. In this case, using the TVTP allows us to test whether a fall in the US stock market return $\left({ }^{z_{t}}\right)$ influences the probabilities of a change from the bull market to the bear market in the MENA countries. Such an impact would clearly identify a contagion process. Following Baur (2003), this type of contagion is qualified by 'mean contagion'. In addition, according to Baur (2003), crises periods could be identified by an increase in volatility which characterises a greater uncertainty. When this volatility has a significant effect on the conditional volatility of other stock markets, then there is evidence of a volatility spillover (Edwards, 1998). However, Baur (2003) distinguishes between volatility

\footnotetext{
${ }^{10}$ When a negative shock generates more volatility than a positive shock of equal magnitude.
} 
spillover and volatility contagion. He supposes that the effect of a volatility increase in one market on the conditional volatility of another stock market takes place only during crises periods. In contrast, volatility spillover can occur at any time. Then, the TVTP allows us to conceptualize the notion of volatility contagion as a significant effect of the volatility increase in the US stock market on the switching regime of conditional volatility of MENA stock markets. Testing both mean contagion and volatility contagion allow us to identify all types of negative effects of the US subprime crisis on the MENA stocks markets since mean contagion is not necessarily associated with the volatility contagion (Baur, 2003).

Thus, following Diebold et al. (1994), the transition probabilities may be written:

$$
\begin{gathered}
p_{00}^{t}=\operatorname{Pr}\left(s_{t}=0 / s_{t-1}=0\right)=\frac{\exp \left(p_{0}+p_{1} z_{t-1}\right)}{1+\exp \left(p_{0}+p_{1} z_{t-1}\right)}=1-p_{10}^{t} \\
p_{11}^{t}=\operatorname{Pr}\left(s_{t}=1 / s_{t-1}=1\right)=\frac{\exp \left(q_{0}+q_{1} z_{t-1}\right)}{1+\exp \left(q_{0}+q_{1} z_{t-1}\right)}=1-p_{01}^{t}
\end{gathered}
$$

where $p_{10}^{t}\left(p_{01}^{t}\right)$ represents the probability of switching from the high-mean, low-variance (low-mean high-variance) state to the low-mean high-variance (high-mean low-variance) state in the next period. The equalities given by equations (3) always hold. Note that following Filardo (1994), we we lagged $z_{t}$ to ensure they are strictly exogenous and must be conditionally uncorrelated to the unobserved state. However, to evaluate the statistical signification of $z_{t-1}$ on the switching of the MENA stock returns between states, we test the null hypothesis of $q_{1}=p_{1}=0$ using the likelihood ratio statistic suggested by Filardo (1994) :

$$
L R=2\left(l_{n c}-l_{c}\right)_{\sim} \chi^{2}(k)
$$

where $l_{c}$ and $l_{n c}$ denote the log likelihood under the null hypothesis and under the unrestricted model, respectively. Under the null hypothesis, the LR statistic has the standard asymptotic $\chi^{2}(k)$ distribution with two degrees of freedom. If the null hypothesis is rejected, we analyze then the marginal effect of ${ }^{z_{t-1}}$ on the switching from the high-mean low-variance regime (bull market) to the low-mean high-variance (bear market) of the MENA stock markets. According to Filardo (1994), the marginal effect of $z_{t-1}$ on $p_{i i}^{t}$ for $i=0,1$ is given by:

$$
\begin{gathered}
\frac{\partial p_{00}^{t}}{\partial z_{t-1}}=p_{1} p_{00}^{t}\left(1-p_{00}^{t}\right) \\
\frac{\partial p_{11}^{t}}{\partial z_{t-1}}=q_{1} p_{11}^{t}\left(1-p_{11}^{t}\right)
\end{gathered}
$$

Since the transition probabilities $p_{00}^{t}$ and $p_{11}^{t}$ are non-negative and range between zero and one in magnitude, then the marginal effect $\partial p_{11}^{t} / \partial z_{t-1}\left(\partial p_{00}^{t} / \partial z_{t-1}\right)$ has the same sign as $q_{1}\left(p_{1}\right)$. Therefore a decrease of the probability of remaining in the high-mean low-variance state is caused by an increase of the US stock market volatility and/or decrease of the US stock market returns. In both cases we may expect to get $\hat{q}_{1<0}$ and/or $\hat{q}_{1>0}$, respectively. 
Since $p_{10}^{t}=1-p_{11}^{t}$ then the probability of switching from bull to bear market increases when the probability of remaining in the high-mean low-variance state $p_{11}^{t}$ decreases. We interpret this result as the indicator of volatility and/or mean contagion effect from the subprime crises to the MENA stock markets.

Like Hamilton (1989) and Diebold et al (1994), we estimate our Markov switching EGARCH model with the fixed transition probabilities or with the time-varying transition probabilities by implementing the EM (Expectation - Maximisation) algorithm ${ }^{11}$, programmed in Gauss 7.0 to obtain maximum likelihood estimates of all the parameters.

\section{Data and empirical results}

\subsection{Data description and GARCH approach}

To identify the MENA 'bear market phases' during the global financial crisis, daily closing stock market index prices from nine countries are examined in this study. We consider the Gulf Cooperation Council (GCC) countries namely Oman (OMA), Bahrain (BAH), Kuwait (KUW) and Dubai (DUB) and non GCC countries, such as Morocco (MOR), Egypt (EGY), Turkey (TUR) and Jordan (JOR). In addition, to investigate the "pure contagion" from the US stock market, we base our analysis on the SP\&500 of the US stock market index price as "ground zero" country. All indices are denominated in US dollars. This allows us to capture the point of view of the international investors. The stock market assets returns are calculated as follows: $r_{t}=100 \times \ln \left(p_{t} / p_{t-1}\right)$, where $p_{t}$ is the stock price on the date t. The data are sampled over the period from February $20^{\text {th }}, 2007$ to March $31^{\text {th }}, 2009$, for a total of 551 observations. All data are extracted from the Datastream database. We use daily return series because high frequency data contains enough numbers of observations over a crisis period (Cerra and Saxena, 2002). In addition, the sample period contains only the subprime crisis windows starting with the first phase in February 2007 (Dooley and Hutchison, 2009).

Table 1 provides the cross-market correlations with the US stock market and some descriptive statistics for all of the countries analyzed.

Table 1. Correlations with the US stock market and descriptive statistics

$\begin{array}{lccccccccccc} & \text { Correlation } & \text { Mean } & \text { Median } & \text { Maximum } & \text { Minimum } & \text { Std. Dev. } & \text { Skewness } & \text { Kurtosis } & \text { J-B } & \text { LB }{ }^{2}(12) \\ \text { OMA } & 0.0337 & -0.0383 & 0.0053 & 8.0395 & -8.6973 & 1.8131 & -0.8129 & 9.5480 & 1045.07^{*} & 453.36^{*} \\ \text { BAH } & 0.0168 & -0.0538 & -0.0084 & 2.6723 & -3.7163 & 0.7113 & -0.9245 & 7.2947 & 501.95^{*} & 197.11^{*} \\ \text { KUW } & -0.0007 & -0.0934 & 0.0060 & 4.8062 & -8.3003 & 1.3561 & -0.7406 & 7.8075 & 580.99^{*} & 246.47^{*} \\ \text { DUB } & 0.1025 & -0.1805 & -0.0116 & 10.218 & -8.8196 & 2.1750 & 0.1120 & 8.0239 & 580.63^{*} & 451.39^{*} \\ \text { MOR } & 0.0756 & -0.0118 & 0.0121 & 6.1258 & -6.4807 & 1.3631 & -0.3616 & 7.0020 & 379.71^{*} & 154.53^{*} \\ \text { EGY } & 0.1752 & -0.0813 & 0.0889 & 5.7576 & -17.494 & 1.9085 & -2.0715 & 17.281 & 5076.86^{*} & 76.075^{*} \\ \text { TUR } & 0.4169 & -0.1328 & -0.0346 & 15.852 & -14.761 & 3.1860 & -0.1575 & 6.1877 & 235.57^{*} & 119.21^{*} \\ \text { JOR } & 0.007 & -0.0223 & 0.0000 & 4.7014 & -4.7229 & 1.4110 & -0.2757 & 4.3417 & 48.31^{*} & 522.43^{*}\end{array}$

\footnotetext{
${ }^{11}$ This algorithm is proposed by Dempster et al. (1977). Dielbold et al. (1994) provide more description for the EM algorithm.
} 
As shown in the first column in table 1, most of the correlation coefficients between the SP500 stock market index return and MENA cross-market seem excessively low. The higher correlation is with Turkey (0.416). As expected, this result confirms that there is not a clear interdependence between the US and the MENA stock markets of our sample. In addition, table 1 shows that Turkish and Dubai stock markets have the highest volatility. For these countries, the standard deviation is respectively equal to 3.186 and 2.175. Both are also associated with a negative average return. Skewness and Kurtosis coefficients of the different series indicate a deviation from the normality assumption. Results of the J-B test show that the null hypothesis of normal distribution is significantly rejected for all stock markets returns. Finally, in order to test the stationarity of our series returns, we apply the Augmented Dickey-Fuller (ADF) and Perron-tests (PP). The results indicate that the null hypothesis of a unit root is always rejected for all series. Hence, all MENA and US returns are $I(0)$ and stationary $^{12}$.

Since we use the daily frequency, our data could be affected by volatility changes over time and volatility clustering (Brunetti et al., 2008). Figure 2 of squared returns could show it. The Ljung-Box (1978) statistic reported in the last column of Table 1, shows that the null hypothesis of uncorrelated squared returns for all countries, is rejected. This result confirms evidence of volatility clustering (Caporale et al., 2006) and consequently the presence of conditional heteroscedasticity effect (Bollerslev, 1986). More formally, P-values results of the $\mathrm{LM}$ and the $\mathrm{LB}^{2}$ of linear AR(1) model in table 2, confirm the strong evidence of ARCH effect in the standardized residuals. All these findings motivate the use of the GARCH approach for capturing the volatility clustering phenomenon. Following Henry (2009), we estimate for each of our MENA stock markets returns a simple AR(1)-EGARCH $(1,1)$ model. This last one also allows the capture of the asymmetry in volatility generated by the leverage effect when a large price increase or a sharp price drop affects differently the volatility (Khedhiri and Muhammad, 2008). The results reported in table 2, show that both the LM and the $\mathrm{LB}^{2}$ tests succeeded in rejecting the ARCH effect for all series except for Jordan that presents a significant autocorrelation for the squared residuals. On the other hand, our EGARCH model captures the asymmetry in the volatility given the negative and significant $\hat{\delta}$ for the majority of countries. All these findings motivate the use of the EGARCH approach for modelling the Markov switching model.

\subsection{Global Financial crisis diagnostics for MENA countries: MS-EGARCH model with Fixed Transition probabilities}

We use the likelihood ratio (LR) tests in order to test the null hypothesis which is the linearity of our EGARCH model. The alternative hypothesis is the Markov-switching EARCH model. although the GARCH approach is able to capture the clustering volatility and/or asymmetry in volatility, it fails to capture structural shifts in the data caused by international financial crises (Edwards and Susmel, 2001). The LR test allows us thus to identify the structural break or switch between the two regimes (stability and crisis) during the subprime turmoil period (2007-2009). However, as noted by Davies (1977), there are nuisance parameters under the null hypothesis since the transition probabilities are unidentified (Henry, 2009). Then, the $L R$ statistic $L R=2\left(\log \left(L_{M S}\right)-\log \left(L_{\text {linear }}\right)\right)$ has a non-standard asymptotic distribution. Therefore,

\footnotetext{
${ }^{12}$ The results are not reported here but are available from the authors upon request.
} 
it seems more judicious to adopt the Davies (1977) upper bound approach as suggested by Garcia and Perron (1996). Assuming that the likelihood ratio has a single peak, the P-values of the upper bound on the $\chi^{2}(5)^{13}$ statistic $^{14}$, are then calculated. The results, reported in table 3, support the rejection of the null hypothesis (the linearity of the model) at a significant level of 5\% for all series with the exception of Jordan stock markets. Our result for Jordan is more difficult to explain. However, the lower liquidity levels and higher sectoral concentration of the Jordan stock market compared to the non GCC countries of our sample (Lagoarde-Segot and Lucy, 2009) could be a part of the explanation for the Jordanian stock market immunity.

Therefore, we can conclude that the MS-EGARCH has identified the regime shifts in the majority of the MENA stock markets. To be more precise, with the exception of Jordan, our results provide evidence that the MENA stock markets have been affected by the global financial crisis and obviously switched from the 'bull market' with a higher return and lower variance to 'bear market' characterised by low-return volatile. As shown in table 3 , we notice that for all countries affected by the global financial crisis, average returns for the regime 0 , are substantially lower than those of regime 1. In contrast, it is clear that unconditional variances for regime 0 , are substantially higher than those of the regime 1 . In fact, daily return

for stable regime $\mu_{1}$ ranges from $3.3 \%$ to $22.1 \%$ while daily return depreciation during crisis regime jumps to $120.1 \%$ for the Dubai stock market. In addition, in regime 1 , the value of the conditional variance intercept ${ } \omega_{1}$ is between -1.244 and 0.779 , whereas, in crisis regime, $\omega_{0}$ is around 0.301 to 1.655 in the Turkey stock market, implying a relatively high level of unconditional volatility for all affected countries. Additionally, in this regime, with the exception of Kuwait, our results find evidence of an asymmetric effect of negative news on conditional volatility. Indeed, for all these affected countries, the values of $\hat{\delta}_{0}$ are negative and are significantly different to zero, implying that negative innovations to returns have a bigger impact on volatility than positive innovations of equal size. Moreover, $\hat{\beta}_{0}$ is significantly different from zero for all affected stock markets with the exception of Morocco. This result shows the persistence in conditional volatility caused by the persistence of shocks arriving in crisis regimes.

Table 3 also reports the unconditional probabilities of two regimes. The unconditional probability $P_{11}$ of being in regime 1, characterized by a higher return and a lower volatility, ranges between $96.5 \%$ for Bahrain and $98.3 \%$ for Morocco. This means that there is a lot of persistence in the no-crisis state for MENA stock markets during the subprime crisis. On the other hand, the unconditional probability $P_{00}$ of staying in a crisis regime with low-return volatility seems smaller than the probability of remaining in regime1. However, $P_{00}$ ranges between $86.7 \%$ for the Bahrain stock market and $96.6 \%$ for the Morocco stock market. The expected duration of crisis regime is between 8.06 days for the Bahrain stock market and 29.41 days for Morocco. The second higher persistence of staying in crisis regime is about 20 days for the Turkey stock market. According to Ismail and Isa (2008), the small persistence of regime 0 compared to the persistence of regime 1 , implies that only extreme events can switch the MENA stock markets from a stability characterized by a bull market to a crisis situation characterized by a bear market.

\footnotetext{
${ }^{13}$ In our case, the number of degrees of freedom is equal to 5 which is equivalent to the additional parameters appearing in the Markov-switching EGARCH model to the EGARCH model.

${ }^{14}$ We assume that the likelihood ratio has a single peak. $\mathrm{P}$-value is given as $\operatorname{Pr}\left(\chi^{2}>\mathrm{LR}\right)+2(\mathrm{LR} / 2)^{\mathrm{D} / 2} \exp (-\mathrm{LR} / 2)$ $/ \Gamma(\mathrm{D} / 2)$ where $\mathrm{D}=5$ parameters and $\Gamma($.$) is the gamma function.$
} 
Figure 2 in appendix 1 exhibits the smoothed probabilities ${ }^{15}$ of being in the crisis regime (bear market) using MS- EGARCH estimations. It is clear that our model identifies the three phases of the subprime financial crisis. For most affected countries, the peaks of smoothed probabilities for bear market regime are synchronized with these three phases. A first phase is characterized by the shorter shocks identified by the shorter bear markets for all MENA countries. Only the Turkey stock market has reacted clearly to the burst of US mortgage bubble in august 2007. The Turkish smoothed probability can identify a long bear market from 19 July 2007 to 22 August 2007. However, the smoothed probabilities of Bahrain, Kuwait, Dubai and Egypt stock markets show a short bear market between one- and three-day bear markets in August 2007. This first phase finishes by shorter bear markets in all stock markets with the exception of Morocco. According to Dooley and Hutchison (2009), these shocks could be explained by the fall in oil prices for GCC countries and the fall of commodity prices for Egypt and Turkey. Smoothed probabilities can also identify the shorter phase 2 from May 2008 to the beginning of August 2008. This second phase is clearly apparent by a persistent bull market (no-crisis regime) for all countries ${ }^{16}$. However, a long bear market has appeared since September 2008 that seems to coincide with the third phase of financial instability on a worldwide level. Moreover, bear market from September and October 2008 (Lehman bankruptcy), is clearly apparent for all affected MENA stock markets. Since this date, we can show that bear market persists during the third phase for all countries.

\footnotetext{
${ }^{15}$ Contrary to the filtered probability that is estimated using information available at time point $t$, the smoothed probability is estimated using full sample information to determine switch occurrences between the unobserved regimes. Following Hamilton (1989), smoothed probability allows to capture the turning points when it is greater than $50 \%$.

${ }^{16}$ When smoothed probability of regime 0 (bear market) is closed to zero, the smoothed probability of regime 1 (bull market) is close to one since $\mathrm{P}_{00}=1-\mathrm{P}_{11}$.
} 
Table 2: Estimation results of AR(1)-EGARCH $(1,1)$

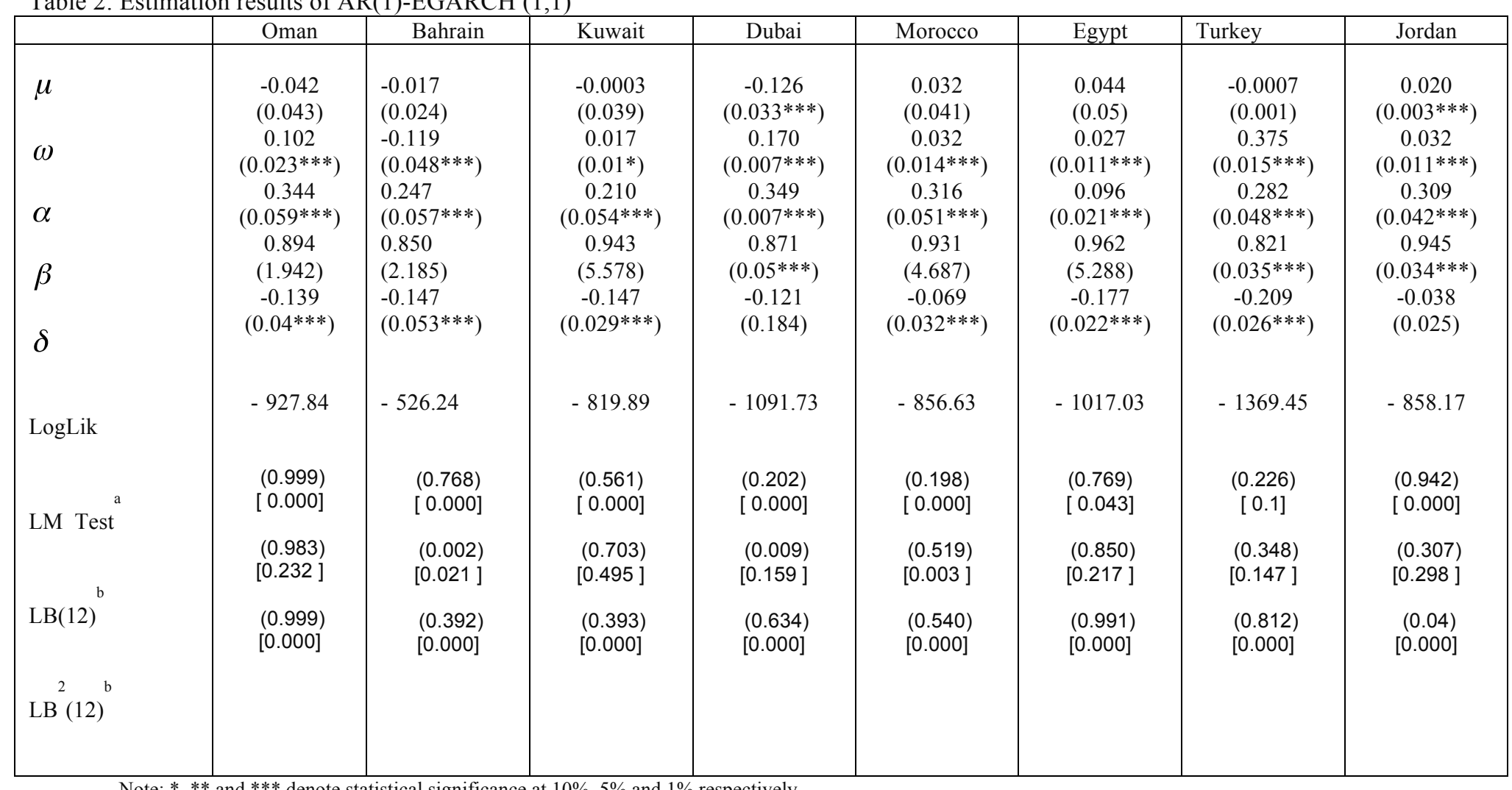

Note: *,** and *** denote statistical significance at $10 \%, 5 \%$ and $1 \%$ respectively.
a. Lagrange multiplier ARCH test on standardized residual. The P-Values are displayed as (.).The P-Values for the linear AR(1) model are displayed as [.].

b. Ljung-Box (1978) tests for standardized residuals and squared standardized residuals with 12 lags. The P-Values are displayed as (.). The P-Values for the linear AR(1) model are displayed as [.]. 
Table 3. Estimation results of the MS-EGARCH(1,1) with the TFP

\begin{tabular}{|c|c|c|c|c|c|c|c|c|}
\hline & Oman & Bahrain & Kuwait & Dubai & Morocco & Egypt & Turkey & Jordan \\
\hline$\mu_{0}$ & -0.546 & -0.345 & -0.494 & -1.201 & -0.197 & -0.813 & -0.665 & -0.205 \\
\hline & $(0.104 * * *)$ & $(0.117 * * *)$ & $(0.172 * *)$ & $(0.277 * * *)$ & $(0.177)$ & $(0.174 * * *)$ & $(0.259 * *)$ & $(0.144)$ \\
\hline$\mu_{1}$ & $\begin{array}{c}0.123 \\
\left(0.038^{* * *}\right)\end{array}$ & $\begin{array}{l}0.033 \\
(0.021 *)\end{array}$ & $\begin{array}{c}0.086 \\
(0.038 * *)\end{array}$ & $\begin{array}{c}0.052 \\
(0.055)\end{array}$ & $\begin{array}{c}0.077 \\
(0.042 *)\end{array}$ & $\begin{array}{c}0.186 \\
0.051 * * *)\end{array}$ & $\begin{array}{c}0.221 \\
0.112 * *)\end{array}$ & 0.106 \\
\hline & 1.299 & 0.301 & 1.014 & 1.4 & 0.947 & $\begin{array}{l}1.279 \\
\text { ( }\end{array}$ & $\begin{array}{c}\left(0.112^{* *}\right) \\
1.655\end{array}$ & $\begin{array}{c}\left(0.048^{* *}\right) \\
0.666\end{array}$ \\
\hline$\omega_{0}$ & $(0.073 * * *)$ & $(0.07 * * *)$ & $\left(0.075^{* * *}\right)$ & $(0.082 * * *)$ & $\left(0.076^{* * *}\right)$ & $(0.072 * * *)$ & $\left(0.13^{* * *}\right)$ & $\left(0.069^{* * *}\right)$ \\
\hline & -0.722 & -1.244 & -0.536 & -0.463 & -0.006 & -0.018 & 0.799 & -1.162 \\
\hline$\omega_{1}$ & $\left(0.046^{* * *}\right)$ & $(0.08 * * *)$ & $\left(0.065^{* * *}\right)$ & $(0.123 * * *)$ & $(0.185)$ & $(0.063)$ & $(0.067 * * *)$ & $\left(0.156^{* * *}\right)$ \\
\hline$\alpha_{0}$ & -1.481 & -0.684 & -0.959 & -1.569 & -0.79 & -1.161 & -0.616 & -1.035 \\
\hline & $(0.060 * * *)$ & $\left(0.06^{* * *}\right)$ & $(0.063 * *)$ & $(0.067 * * *)$ & $\left(0.065^{* * *}\right)$ & $(0.058 * * *)$ & $(0.131 * * *)$ & $(0.058 * * *)$ \\
\hline$\alpha_{1}$ & $\begin{array}{c}-0.224 \\
(0.041 * * *)\end{array}$ & $\begin{array}{l}0.155 \\
(0.042 * * *)\end{array}$ & $\begin{array}{c}0.351 \\
\left(0.055^{* * *}\right)\end{array}$ & $\begin{array}{c}-0.695 \\
(0.099 * * *)\end{array}$ & $\begin{array}{c}0.468 \\
\left(0.155^{* * *}\right)\end{array}$ & $\begin{array}{c}-0.064 \\
(0.051)\end{array}$ & $\begin{array}{c}-0.345 \\
\left(0.146^{* * *}\right)\end{array}$ & $\begin{array}{c}-1.024 \\
(0.228 * * *)\end{array}$ \\
\hline & 0.317 & 0.329 & 0.428 & 0.317 & 0.452 & 0.464 & 0.567 & 0.362 \\
\hline$P_{0}$ & $(0.021 * * *)$ & $(0.049 * * *)$ & $(0.032 * * *)$ & $(0.023 * * *)$ & $(0.048 * * *)$ & $(0.028 * * *)$ & $(0.053 * * *)$ & $(0.028 * * *)$ \\
\hline$\beta_{1}$ & 0.185 & 0.21 & -0.13 & 0.308 & 0.088 & -0.133 & 0.221 & 0.364 \\
\hline$\rho_{1}$ & $(0.026 * * *)$ & $\left(0.051^{* * *}\right)$ & $(0.044 * *)$ & $\left(0.125^{* *}\right)$ & $(0.132)$ & $(0.041 * * *)$ & $\left(0.076^{* *}\right)$ & $(0.188 * *)$ \\
\hline & -0.198 & -0.197 & -0.196 & -0.206 & -0.175 & -0.184 & -0.642 & -0.021 \\
\hline$\delta_{0}$ & $(0.021 * * *)$ & $\left(0.033^{* * *}\right)$ & $(0.031 * * *)$ & $(0.017 * * *)$ & $(0.039 * * *)$ & $(0.026 * * *)$ & $\left(0.215^{* *}\right)$ & $(0.029)$ \\
\hline & -0.882 & -0.830 & 0.011 & -0.7 & -0.076 & -0.118 & -0.329 & -0.508 \\
\hline$\delta_{1}$ & $(0.022 * * *)$ & $\left(0.075^{* * *}\right)$ & $(0.138)$ & $(0.123 * * *)$ & $(0.039 *)$ & $(0.028 * * *)$ & $\left(0.115^{* *}\right)$ & $(0.14 * * *)$ \\
\hline$P_{00}$ & 0.918 & 0.876 & 0.941 & 0.877 & 0.966 & 0.912 & 0.95 & 0.959 \\
\hline${ }^{1} 00$ & $(0.041 * * *)$ & $(0.042 * * *)$ & $(0.446 * *)$ & $(0.271 * * *)$ & $(0.557 *)$ & $(0.128 * * *)$ & $(0.418 * *)$ & $(0.478 * *)$ \\
\hline$P_{11}$ & $\begin{array}{c}0.975 \\
(0.239 * * *)\end{array}$ & $\begin{array}{l}0.965 \\
(0.341 * *)\end{array}$ & $\begin{array}{c}0.975 \\
(0.441 * *)\end{array}$ & $\begin{array}{c}0.969 \\
(0.269 * * *)\end{array}$ & $\begin{array}{c}0.983 \\
(0.443 * *)\end{array}$ & $\begin{array}{c}0.97 \\
(0.159 * * *)\end{array}$ & $\begin{array}{c}0.971 \\
\left(0.295^{* * *}\right)\end{array}$ & $\begin{array}{c}0.979 \\
(0.458 * *)\end{array}$ \\
\hline & -863.5 & -493.27 & -797.72 & -1052.77 & -846.59 & -985.46 & -1356.48 & -857.5 \\
\hline LR & $\begin{array}{c}128.68 * * * \\
{[0.000]}\end{array}$ & $\begin{array}{l}65.94 \\
\quad[0.000]\end{array}$ & $\begin{array}{c}44.34 \\
{[0.000]}\end{array}$ & $\begin{array}{c}77.92 \\
{[0.000]}\end{array}$ & $\begin{array}{c}20.08 \\
{[0.0209]}\end{array}$ & $\begin{array}{c}63.14 \\
{[0.000]}\end{array}$ & $\begin{array}{c}25.94 \\
{[0.0021]}\end{array}$ & $\begin{array}{c}1.34 \\
{[0.999]}\end{array}$ \\
\hline$E(D)$ & 12.19 & 8.06 & 16.94 & 8.13 & 29.41 & 11.36 & 20 & - \\
\hline
\end{tabular}

The figures in parentheses are standard error
The P-Values for Davies test are displayed as [.]. 


\subsection{Identifying the US subprime "contagion" to MENA stock markets: MS-EGARCH with varying transition probabilities}

As noted earlier, the use of the TVTP assesses the impact of the US subprime crisis on the MENA stock markets. Our purpose is to investigate whether the dynamic phases of MENA stock returns, which show a relative coincidence with the third phase of the subprime crisis, are affected by a fall in the US stock market returns (mean contagion) or/and a volatility increase in the US stock market returns (volatility contagion). To this purpose we test, as a first step, for significance of the time-varying probabilities to govern movements across regimes. In a second step, we investigate whether a decrease (increase) in the US returns (US returns volatility) will lead to decrease the probabilities of remaining in a no-crisis regime (bull market).

Table 4. Estimations results with the TVPT

\begin{tabular}{|c|c|c|c|c|c|c|c|}
\hline & Oman & Bahrain & Kuwait & Dubai & Morocco & Egypt & Turkey \\
\hline$\mu_{0}$ & -0.580 & -0.326 & -0.498 & -1.044 & -0.345 & -0.779 & -0.813 \\
\hline$\mu_{0}$ & $(0.207 * *)$ & $(0.112 * *)$ & $(0.154 * * *)$ & $\left(0.207^{* * *}\right)$ & $\left(0.185^{*}\right)$ & $(0.241 * * *)$ & $(0.094 * * *)$ \\
\hline$\mu_{1}$ & 0.119 & 0.038 & 0.186 & 0.054 & 0.086 & 0.233 & 0.227 \\
\hline & $\begin{array}{c}(0.03510) \\
1.410\end{array}$ & $\begin{array}{c}\left(0.021^{*}\right) \\
0.393\end{array}$ & $\begin{array}{c}\left(0.086^{* *}\right) \\
0.852\end{array}$ & $\begin{array}{c}(0.055) \\
1.648\end{array}$ & $\begin{array}{c}\left(0.043^{* *}\right) \\
0.236\end{array}$ & $\begin{array}{c}(0.057 * * *) \\
-2.473\end{array}$ & $\begin{array}{c}\left(0.114^{* *}\right) \\
0.657\end{array}$ \\
\hline$\omega_{0}$ & $(0.078 * * *)$ & $\left(0.075^{* * *}\right)$ & $(0.080 * * *)$ & $(0.088 * * *)$ & $\left(0.15^{*}\right)$ & $(2.891)$ & $(0.067 * * *)$ \\
\hline & -0.190 & -1.017 & -0.477 & 0.094 & 0.001 & -3.538 & -0.679 \\
\hline$\omega_{1}$ & $(0.148)$ & $\left(0.15^{* * *}\right)$ & $(0.079 * * *)$ & $\left(0.058^{*}\right)$ & $(0.116)$ & $(2.491 *)$ & $(0.098 * * *)$ \\
\hline$\alpha_{0}$ & $\begin{array}{c}-1.260 \\
\left(0.065^{* * *}\right)\end{array}$ & $\begin{array}{c}-0.446 \\
\left(0.065^{* * *}\right)\end{array}$ & $\begin{array}{c}-0.817 \\
(0.067 * * *)\end{array}$ & $\begin{array}{c}-1.457 \\
(0.072 * * *)\end{array}$ & $\begin{array}{c}-0.819 \\
\left(0.091^{* * *}\right)\end{array}$ & $\begin{array}{l}-4.435 \\
(3.938)\end{array}$ & $\begin{array}{c}-0.657 \\
(0.078 * * *)\end{array}$ \\
\hline$\alpha$ & 0.527 & 0.735 & 0.360 & $\begin{array}{l}(0.0 / 246 \\
-0.246\end{array}$ & -0.251 & $\begin{array}{l}-2.735 \\
-2.75)\end{array}$ & -0.352 \\
\hline$\omega_{1}$ & $(0.143 * * *)$ & $(0.122 * * *)$ & $(0.058 * * *)$ & $\left(0.06^{* * *}\right)$ & $\left(0.145^{* *}\right)$ & (3.251) & $(0.164 * * *)$ \\
\hline$\beta_{0}$ & -0.074 & 0.509 & -0.115 & 0.007 & 0.514 & 0.552 & 0.618 \\
\hline & $(0.153)$ & $\left(0.145^{* * *}\right)$ & $(0.141)$ & $(0.105)$ & $(0.395)$ & (0.6) & $(0.063 * * *)$ \\
\hline$\beta_{1}$ & $\begin{array}{l}-0.251 \\
(0223)\end{array}$ & 0.059 & -0.048 & -0.019 & $\begin{array}{l}-0.283 \\
0.00 * *)\end{array}$ & $\begin{array}{c}0.584 \\
0.293 * *)\end{array}$ & $\begin{array}{c}0.603 \\
057 * *)\end{array}$ \\
\hline$\delta_{0}$ & $\begin{array}{l}(0.225) \\
-0.181\end{array}$ & $\begin{array}{l}(0.198) \\
-0.189\end{array}$ & $\begin{array}{l}0.073) \\
-0.184\end{array}$ & $\begin{array}{l}(0.044) \\
-0.186\end{array}$ & 0.32 & $\begin{array}{c}\left(0.293^{*}\right) \\
-1.02\end{array}$ & -0.123 \\
\hline & $(0.032 * * *)$ & $\left(0.036^{* * *}\right)$ & $\left(0.033^{* * *}\right)$ & $(0.03 * * *)$ & $\left(0.095^{* * *}\right)$ & $(0.917)$ & $(0.027 * * *)$ \\
\hline$\delta_{1}$ & $\begin{array}{c}-0.151 \\
(0.036 * * *)\end{array}$ & $\begin{array}{c}-0.195 \\
(0.041 * * *)\end{array}$ & $\begin{array}{c}-0.111 \\
(0.033 * * *)\end{array}$ & $\begin{array}{l}-0.053 \\
(0.043)\end{array}$ & $\begin{array}{c}0.191 \\
(0.213)\end{array}$ & $\begin{array}{c}0.188 \\
(0.217)\end{array}$ & $\begin{array}{l}-0.023 \\
(0.023)\end{array}$ \\
\hline $\mathrm{p}_{0}$ & 2.577 & 2.197 & 2.804 & 2.128 & 3.783 & 2.311 & 2.902 \\
\hline & $(0.387 * * *)$ & $(0.247 * * *)$ & $(0.413 * * *)$ & $(0.253 * * *)$ & $(0.627 * * *)$ & $(0.336 * * *)$ & $(0.29 * * *)$ \\
\hline $\mathrm{q}_{0}$ & 4.287 & 3.032 & 3.598 & 3.446 & 4.319 & 3.208 & 3.36 \\
\hline & $(0.527 * * *)$ & $(0.217 * * *)$ & $(0.367 * * *)$ & $(0.244 * * *)$ & $\left(0.475^{* * *}\right)$ & $(0.29 * * *)$ & $(0.413 * * *)$ \\
\hline $\mathrm{p}_{1}$ & -0.106 & -0.225 & -0.035 & -0.246 & -1.298 & -0.027 & -0.049 \\
\hline & $(0.124)$ & $\left(0.084^{* *}\right)$ & $(0.132)$ & $(0.084 * *)$ & $\left(0.373^{* * *}\right)$ & $(0.114)$ & $(0.163)$ \\
\hline $\mathrm{q}_{1}$ & $\begin{array}{c}-1.384 \\
\left(0.606^{* *}\right)\end{array}$ & $\begin{array}{c}1.22 \\
(0.394 * * *)\end{array}$ & $\begin{array}{c}0.389 \\
(0.272)\end{array}$ & $\begin{array}{c}0.058 \\
(0.134)\end{array}$ & $\begin{array}{c}0.436 \\
(0.151 * *)\end{array}$ & $\begin{array}{c}0.348 \\
(0.094 * * *)\end{array}$ & $\begin{array}{c}0.395 \\
(0.13 * * *)\end{array}$ \\
\hline LogLik & -860.526 & -487.791 & -797.033 & -1051.95 & -838.624 & -981.168 & -1352.83 \\
\hline LR & 5,948 & $10,958^{* *}$ & 1,374 & 1,64 & $15,932^{* * *}$ & $8,584^{* *}$ & $7,3^{* *}$ \\
\hline $\begin{array}{c}\text { Mean Contagion } \\
\text { result }\end{array}$ & no & yes & no & no & yes & yes & yes \\
\hline
\end{tabular}

Note: The figures in parentheses are standard error of the estimators.

* Significance of the coefficients at the $5 \%$ level. ** Idem $1 \%$ level. 
Table 5. Estimations results with the TVPT for the contagion volatility

\begin{tabular}{|c|c|c|c|c|c|c|c|}
\hline & Oman & Bahrain & Kuwait & Dubai & Morocco & Egypt & Turkey \\
\hline & -0.402 & -0.293 & -0.488 & -0.179 & -0.248 & -0.717 & -0.852 \\
\hline$\mu_{0}$ & $\left(0.258^{*}\right)$ & $\left(0.109^{* *}\right)$ & $(0.146 * * *)$ & $(0.259)$ & $\left(0.157^{*}\right)$ & $(0.136 * * *)$ & $\left(0.145^{* * *}\right)$ \\
\hline & 0.128 & 0.037 & 0.080 & -0.041 & 0.08 & 0.218 & 0.226 \\
\hline$\mu_{1}$ & $(0.033 * * *)$ & $(0.022 *)$ & $\left(0.036^{* *}\right)$ & $(0.06)$ & $\left(0.041^{* *}\right)$ & $\left(0.051^{* * *}\right)$ & $\left(0.114^{* *}\right)$ \\
\hline$\omega_{0}$ & 1.139 & 0.255 & 0.869 & 1.038 & 0.695 & 1.692 & 0.512 \\
\hline$\omega_{0}$ & $(0.105 * * *)$ & $(0.077 * * *)$ & $(0.064 * * *)$ & $(0.094 * * *)$ & $(0.092 * * *)$ & $(0.167 * * *)$ & $(0.071 * * *)$ \\
\hline & -1.642 & -1.197 & -0.497 & -0.792 & 0.009 & 0.492 & -0.855 \\
\hline$\omega_{1}$ & $(0.292 * * *)$ & $(0.237 * * *)$ & $(0.112 * * *)$ & $(0.242 * * *)$ & (0.104) & $(0.147 * * *)$ & $(0.188 * * *)$ \\
\hline$\alpha_{0}$ & $\begin{array}{c}-1.145 \\
(0.072 * * *)\end{array}$ & $\begin{array}{c}-0.356 \\
\left(0.06^{* * *}\right)\end{array}$ & $\begin{array}{c}-0.819 \\
(0.056 * * *)\end{array}$ & $\begin{array}{c}-0.989 \\
(0.072 * * *)\end{array}$ & $\begin{array}{c}-1.671 \\
\left(0.075^{* * *}\right)\end{array}$ & $\begin{array}{c}-1.182 \\
(0.171 * * *)\end{array}$ & $\begin{array}{c}-0.606 \\
(0.081 * * *)\end{array}$ \\
\hline & -1.517 & 0.791 & 0.495 & -0.781 & -0.236 & -0.442 & -0.573 \\
\hline$\alpha_{1}$ & $(0.332 * * *)$ & $(0.136 * * *)$ & $(0.096 * * *)$ & $\left(0.27^{* *}\right)$ & $(0.06 * * *)$ & $\left(0.147^{* * *}\right)$ & $\left(0.348^{*}\right)$ \\
\hline$\beta_{0}$ & 0.457 & 0.473 & 0.047 & 0.693 & -0.344 & -0.275 & 0.676 \\
\hline & $\left(0.317^{*}\right)$ & $\left(0.286^{*}\right)$ & $(0.163 * * *)$ & $(0.495)$ & $\left(0.075^{* * *}\right)$ & $\left(0.16^{*}\right)$ & $(0.122 * * *)$ \\
\hline$\beta_{1}$ & 0.758 & -0.074 & -0.31 & 0.39 & -0.356 & -0.498 & 0.605 \\
\hline & $(0.843)$ & $(0.262)$ & $(0.156 * * *)$ & $(0.35)$ & $(0.087 * * *)$ & (0.464) & $(0.081 * * *)$ \\
\hline$\delta_{0}$ & -0.225 & -0.197 & -0.179 & -0.182 & 0.571 & 0.009 & -0.124 \\
\hline & $(0.033 * * *)$ & $(0.038 * * *)$ & $(0.033 * * *)$ & $(0.03 * * *)$ & $(0.034 * * *)$ & $(0.143)$ & $(0.027 * *)$ \\
\hline$\delta_{1}$ & $\begin{array}{c}-0.189 \\
(0.042 * *)\end{array}$ & $\begin{array}{c}-0.198 \\
\left(0.07^{* *}\right)\end{array}$ & $\begin{array}{c}-0.107 \\
(0.033 * * *)\end{array}$ & $\begin{array}{c}0.1 \\
(0.064 *)\end{array}$ & $\begin{array}{l}-0.031 \\
(0.08)\end{array}$ & $\begin{array}{c}0.059 \\
(0.078)\end{array}$ & $\begin{array}{c}-0.036 \\
(0.022 *)\end{array}$ \\
\hline $\mathrm{p}_{0}$ & $\begin{array}{l}2.360 \\
(0.426 * * *)\end{array}$ & $\begin{array}{l}2.087 \\
(0.328 * * *)\end{array}$ & $\begin{array}{c}2.852 \\
(0.483 * * *)\end{array}$ & $\begin{array}{c}2.113 \\
(0284 * * *)\end{array}$ & $\begin{array}{l}3.271 \\
(0.446 * * *)\end{array}$ & $\begin{array}{l}2.373 \\
(0.321 * * *)\end{array}$ & $\begin{array}{c}2.762 \\
(0.478 * * *)\end{array}$ \\
\hline $\mathrm{q}_{0}$ & 3.674 & 3.209 & 3.806 & 2.895 & 4.26 & 3.329 & 3.469 \\
\hline & $(0.426 * * *)$ & $\left(0.206^{* * *}\right)$ & $(0.427 * * *)$ & $(0.329 * * *)$ & $\left(0.451^{* * *}\right)$ & $(0.313 * * *)$ & $(0.616 * * *)$ \\
\hline $\mathrm{p}_{1}$ & -0.251 & -0.278 & -0.203 & -0.275 & 0.300 & -0.348 & 0.534 \\
\hline & $(0.052 * * *)$ & $(0.048 * * *)$ & $(0.057 * * *)$ & $(0.041 * * *)$ & $(0.042 * * *)$ & $(0.104 * * *)$ & $(0.058 * * *)$ \\
\hline $\mathrm{q}_{1}$ & $\begin{array}{l}-0.157 \\
\left(0.056^{* *}\right)\end{array}$ & $\begin{array}{c}-0.688 \\
(0.287 * *)\end{array}$ & $\begin{array}{c}-0.305 \\
(0.141 * *)\end{array}$ & $\begin{array}{c}-0.122 \\
(0.044 * *)\end{array}$ & $\begin{array}{l}0.341 \\
\left(0.055^{* * *}\right)\end{array}$ & $\begin{array}{c}-0.157 \\
(0.04 * * *)\end{array}$ & $\begin{array}{c}0.114 \\
(0.063 *)\end{array}$ \\
\hline LogLik & -854.014 & -488.825 & -796.851 & -1046.178 & -840.606 & -975.102 & -1352.36 \\
\hline LR & $18.972^{* * *}$ & $8.89^{* *}$ & 1.738 & $13.184^{* * *}$ & $11.968^{* * *}$ & $20.716^{* * *}$ & $8.24^{* *}$ \\
\hline $\begin{array}{l}\text { Volatility Contagion } \\
\text { result }\end{array}$ & yes & yes & no & yes & no & yes & no \\
\hline
\end{tabular}

Empirical results of mean and volatility contagion are presented in table 4 and table 5 respectively. For the first step, we use the likelihood ratio (LR) tests in order to compare the fixed transition probabilities model with two time-varying transition probabilities models. In the first model, the probability of a switch in regime is assumed to vary with US return. In addition, in the second model, the probability of a switch in regime is assumed to vary with US volatility. We test in these two cases for the null hypothesis according to which the transition probabilities are constant. As reported in Table 4, results support the rejection of the null hypothesis at a significant level of 5\% for Bahrain, Morocco, Egypt and Turkey. In these cases, the LR statistic exceeds the $\chi^{2}$ (2) that is equal to 5.99 and 9.21 assuming a $5 \%$ and $1 \%$ level of confidence, respectively. Hence, we can assert that there is evidence of a statistically significant response of these countries stock markets to the US stock markets return variation. In addition, the results in Table 5 indicate that the LR statistic of Oman, Bahrain, Dubai, Egypt and Turkey exceeds the $\chi^{2}(2)$. These results prove that US volatility provides useful information in explaining the time variation in the transition probabilities. However, it turns out that the Kuwait stock market is not affected by the US stock market return variation and volatility. This immunity to shocks originated in the US does not exclude the possibility that 
the Kuwait stock market could be affected by other regional shocks explaining switches between bull and bear markets.

In addition, as with the fixed transitions probabilities, the results of selected countries in Table 4 and 5 are also consistent with the existence of two regimes since the intercept of model seems lower in the "low mean-high variance" regime than in the "high mean-low variance" regime and the intercept of the conditional variance is substantially higher in the bear market than in the bull market.

In the countries for which we have revealed a strong presumption of "contagion" using LR test, we next analyze the marginal effect of the US stocks returns and US volatility on stock markets of these countries in order to confirm the existence of a mean contagion and/or volatility contagion. Table 4 and 5 present the coefficient estimates of $\left(p_{0}, p_{1}, q_{0}, q_{1}\right)$ which enable us to identify the direction of the impact on the various MENA stock markets, according to the criteria discussed above.

For countries where a significant impact of US returns is verified (Table 4), estimates $\hat{q}_{1}$ have a plausible sign and is statistically significant. $\hat{q}_{1}$ is positive and equal to $1.22,0.436$, 0.348 and 0.395 for Bahrain, Morocco, Egypt and Turkey, respectively. Given the positive sign, the fall in the US stock market return raises the probability of switching from high mean-low variance regime to the low mean- high variance regime in MENA stock markets. This result provides evidence that the shocks of US return have a negative effect on the probability of remaining in the no-crisis regime and send these MENA stock markets into bear market. We could interpret this result as the evidence of mean contagion from the US Subprime financial crisis to Bahrain, Morocco, Egypt and Turkey.

Moreover, volatility contagion can be found for Oman, Bahrain, Dubai and Egypt stock markets (Table 5). With the exception of Turkey from countries where a significant impact of US volatility is verified, estimates $\hat{q}_{1}$ for all countries have a negative sign and are statistically significant. These findings provide evidence that an increase in the US stock market volatility raises the probability of switching from high mean-low variance regime to the low mean-high variance regime. That is, a negative reaction occurs in Oman, Bahrain, Dubai and Egypt stock markets due to the US stock market volatility shocks during the subprime financial crisis.

Overall, our results suggest that the US stock market return is statistically important in the prediction of low-returns, high variance regime for most MENA stock markets during the subprime financial crisis. We find that there is mean and volatility contagion. Both types of contagion lead to an increased likelihood of occurrence of crisis in these countries. This result brings to light the effect of the subprime crisis on these MENA markets sentiments. According to Goldstein (1998), the subprime crises played a 'wake-up call' role for the MENA investors, essentially domestic investors whose changes in expectations are behind the switch from a good to a bad (crisis) equilibrium (Masson, 1999). By contrast, Kuwait stock market does not seem to be significantly influenced by the US stock market, which implies that this market is relatively immune to shocks originating from the US. However, evidence of bear market for Kuwait stock market could be generated by other regional or other international shocks during the global financial crisis, for example a fall in the oil price at the end of 2008. In addition, our test does not identify any switching of mean and volatility for the Jordan stock market during the subprime crisis.

\section{Conclusion}


This paper is an attempt to investigate whether any of the developing stock markets of MENA region have been affected by the financial "contagion" of the 2007 US subprime crisis. To this end, we have extended the Cerra and Saxena (2002) methodology using a MS-EGARCH model with time-varying transition probabilities in order to test "contagion" from the US stock market (ground-zero country) to eight MENA stock markets. Our Markov switching analysis differs from earlier studies in two important ways. Firstly, our methodology analyses directly the individual stock market sentiment in contrast to a correlation approach which tests the structural change of links between markets. Furthermore, this paper is the first attempt to investigate the effect of the subprime crisis on the MENA stock markets sentiment. Secondly, the MS-EGARCH model is used for the first time in order to identify the contagion effect during the international financial crisis.

Estimating our MS-EGARCH model with daily stock market assets returns data, ranging from February 20, 2007 to March 31, 2009, we have shown that our model clearly captures the persistent phase of a bear market in all the MENA stock markets of our sample with the exception of Jordan. This bear market phase which started in September 2008 coincides with the third phase of the current global financial crisis. Besides, we have found mean and volatility contagion in the Bahrain and Egypt stock markets. Our results highlight a significant increase in the likelihood of crisis occurrence characterized by low return and high volatility, following the US stock market fall and the US volatility rise. Our study also reveals a mean contagion to Morocco and Turkey, while the contagion to Oman and Dubai is explained only by the US volatility (volatility contagion). Our results are directly comparable to previous studies analysing contagion vulnerability of small emerging markets such as African and MENA markets. They are in line with the evidence of Collins and Biekpe (2002) and Lagoarde-Segot and Lucey (2009) concerning contagion vulnerability of Morocco, Egypt and Turkey. Nevertheless, our results do not confirm the vulnerability of the Jordan stock market during the global financial crisis. Moreover, we find out for the first time, the vulnerability of the GCC region to contagion of the global financial crisis. It should be noted, however, that our methodology focuses on changes in market sentiment during the subprime crisis, rather than occurrence of the stock market crash in the MENA region.

The fact that very different countries have been contaminated, as shown in our study, tends to give credence to the global characteristic of the crisis. On the one hand, among affected market in our sample, there is for example Morocco, one of the smallest markets in the MENA region, with a market capitalization equal to $\$ 9.2$ billion in 2009, and only 56 listed stocks (see table 3 in appendix 2). We have also larger stock markets (for example: Egypt and Turkey). If we consider the stock market capitalization to GDP ratio (table 4 in appendix 2), which is generally considered as an indicator of over (if greater that 100) or undervaluation (if smaller than 100), we have overvalued (Bahrain) as well as undervalued markets (Egypt, Oman). Thus, we can deduce from our research the important magnitude of the current financial crisis which is affecting a large variety of markets, regardless of their characteristics (size of the market, liquidity, stage of liberalization, level of international financial integration and so on). On the other hand, our sample also includes GCC and non GCC countries. This implies that the current financial crisis is not related to the type of specialization of the countries under consideration (oil exporting countries or more diversified economies). These findings might suggest that international portfolio diversification in segmented MENA equity markets has not really been an efficient instrument of immunization against the risk of contagion.

Moreover, after they had devoted significant efforts in order to strengthen financial intermediation by promoting market-based mechanisms, modernizing banking practices, adopting international standards of supervision, as well as building the infrastructure of 
dynamic equity markets (Egypt, Morocco and Gulf Cooperation Council countries), the fact that some MENA countries are clearly victims of a "contagion" can legitimize the choice to stop or even to reverse the process of economic and financial liberalization, so as to reduce reliance on international capital investment and on trade relations (foreign outlets and supplying) and to base development on domestic resources and activities. Today, some experts are singing the praises of disconnection and celebrating the emergence of a new refocused, inward-looking mode of development.

In order to support such a policy, it would be necessary to establish a causal relationship between international commercial and financial integration and "contagion". It would be necessary to prove that the developing and emerging counties which have been spared the devastating effects of financial turmoil and contagion, because of their lack of integration into the international financial system and the low level of capital inflows. In fact, this proof remains to be shown. In one sense, our study tends to suggest the opposite, without establishing any reliable proof, due to the small number of countries in our sample. No doubt that a complete and undifferentiated withdrawal into oneself might be a good recipe for low growth, high unemployment, and losing opportunities to benefit from the global evolution. Nevertheless, strategies of insulation in order to protect the economy from the negative externalities of financial liberalisation can be considered as a possible and, in some cases, as a desirable solution, providing that it does not push the country to the sidelines of international competition. The experience of Chile which succeeded in protecting itself from contagion during the 90's by imposing a tax on short-term inflows of foreign capital has been thoroughly studied (see for example Ito and Portes, 1998; Eichengreen, 1999; and Edwards, 1999, among others).

To preserve their economies from the excesses of globalization, MENA countries should rather further strengthen their domestic financial systems by enhancing prudential regulations and supervision. They should continue their efforts and progress in deepening capital markets so as to improve liquidity and in diversifying sources of financing.

No need to throw the baby out with the bathwater. 


\section{References}

Abiad A. (2003), "Early Warning Systems: A Survey and a Regime-Switching Approach". IMF Working Paper, WP/03/32.

Alper C.E. and Yilmaz K. (2004), "Volatility and contagion: evidence from the Istanbul stock exchange", Economic Systems, 28(4), pp. 353-367.

Baur D. (2003), "Testing for contagion - mean and volatility contagion". Journal of Multinational Financial Management, 13 (4), pp. 405-422.

Bekaert G., Harvey C. and Lundblad C. (2005), "Does financial liberalisation spur growth?". Journal of Financial Economics, 77 (1), pp. 3-55.

Bollerslev T. (1986), "Generalized Autoregressive Conditional Heteroskedasticity”, Journal of Econometrics, 31(3), pp. 307-327.

Brunetti C., Scotti C., Mariano R.S. and Tan A.H.H. (2008), "Markov switching GARCH models of currecy turmoil in Southeast Asia", Emerging Markets Review, 9 (2), pp. 104-128.

Cai, J., (1994), “A Markov model of switching-regime ARCH”, Journal of Business \& Economic Statistics 12 (3), pp. 309-316.

Calvo G.A. (1999), "Contagion in emerging markets: When Wall Street is a carrier". University of Maryland. Mimeograph.

Calvo S. and Reinhart C. (1996), "Capital flows to emerging countries: Is there evidence of contagion effects?". In Calvo G., Goldestein M. and Hochreiter E. (ed.), Private capital flows to emerging markets, Institute for International Economics.

Caporale G. M., Pittis N. and Spagnolo N. (2006), "Volatility transmission and financial crises", Journal of Economics and Finance, 30(3), pp. 376-390.

Caramazza F., Luca R. and Ranil S. (2004), "International contagion in currency crises". Journal of International Money and Finance, 23(1), pp. 51-70.

Cerra V. and Saxena S. C. (2002), "Contagion, Monsoons, and Domestic Turmoil in Indonesia's Currency Crisis”. Review of International Economics, Vol. 10, pp. 36-44,

Chen S.-S. (2009), "Predicting the bear stock market: Macroeconomic variables as leading indicators", Journal of Banking and Finance 33(2), pp. 211-223.

Chen S.-S. (2010), “ Do higher oil prices push the stock market into bear territory?”, Energy Economics, 32(2), pp. 490-495.

Cheng A-R, Jahan-Parvar M. R. and Rothman P. (2009), "An empirical investigation of stock market behavior in the Middle East and North Africa'. Journal of Empirical Finance, 17, pp. 413-427.

Collins D. and Abrahamson M. (2006), "Measuring the cost of equity in African financial markets". Emerging Markets Review, 7, pp. 67-81.

Collins D. and Biekpe N. (2003), “Contagion: a fear for African equity markets?". Journal of Economics \& Business, 55(5), pp. 405-426.

Corsetti G., Pericoli M. and Sbracia M. (2005), "Some contagion, some interdependence: More pitfalls in tests of financial", Journal of International Money and Finance, 24(8), pp. 1177-1199.

Corsetti G., Pesenti P., Roubini N. and Tille C. (1999), "Competitive devaluations: a welfarebased approach". NBER Working Paper Series, 6889.

Davies R. B. (1977), "Hypothesis testing when a nuisance parameter is present only under the alternative". Biometrika, 64, pp. 247-54.

Dempster A.P., Laird N.M. and Rubin D.B. (1977), "Maximum likelihood from incomplete data via the EM algorithm", Journal of the Royal Statistical Society, 39, pp. 1-38.

Diebold F.X., Lee J.-H. and Weinbach G. (1994), "Regime Switching with Time-Varying Transition Probabilities". In Hargreaves C. (ed.), Nonstationary Time Series Analysis and 
Cointegration. (Advanced Texts in Econometrics, C.W.J. Granger and G. Mizon, eds.), Oxford University Press. Oxford: 283-302.

Dooley M. and Hutchison M. (2009), "Transmission of the U.S. Subprime Crisis to Emerging Markets: Evidence on the Decoupling-Recoupling Hypothesis". Paper prepared for the JIMF/Warwick Conference, March.

Edwards S. (1998), "Interest rate volatility, contagion and convergence: an empirical investigation of the cases of Argentina, Chile and Mexico", Journal of Applied Economics, $1(1)$, pp.55-86.

Edwards S. (1999), "How effective are controls on capital inflows? An evaluation of Chile's experience". Working paper, June.

Edwards S. and Susmel R. (2001), "Volatility dependence and contagion in emerging equity markets", Journal of Development Economics, 66(2), pp. 505-532.

Eichengreen B. (1999), Toward a New International Financial Architecture. Institute for International economics, Washington D.C.

Eichengreen B., Rose A. K. and Wyplosz C. (1996), "Contagious currency crises". NBER Working Paper no. 5681. Cambridge, Mass.: National Bureau of Economic Research.

Filardo A.J. (1994), "Business cycle phases and their transitional dynamics", Journal of Business and Economic Statistics, 12 (3), pp. 299-308.

Flavin T., Panopoulou E. and Unalmis D. (2008), " On the stability of domestic financial market linkages in the presence of time-varying volatility", Emerging Markets Review, 9(4), pp. 280-301.

Forbes K. and Rigobon R. (2001), "Contagion in Latin America: Definition, Measurement, and Policy Implications", Mit-Sloan school of management and NBER, January 17.

Garcia R. and Perron P. (1996), "An analysis of the real interest rate under regime shifts", Review of Economics and Statistics, 78, pp. 111-125.

Gerlach S. and Smets F. (1995), "Contagious Speculative Attacks", European Journal of Political Economy, 11, pp. 45-63.

Glick R. and Rose A.K. (1999), "Contagion and trade: Why are currency crises regional?" Journal of International Money and Finance, 18, pp. 603-17.

Goldstein, M. (1998), "The Asian financial crises: causes, cures and systemic implication" Policy Analysis in International Economics, Institute for International Economics.

Gray S.F. (1996), "Modeling the conditional distribution of interest rates as a regime switching process", Journal of Financial Economics, 42, pp. 27-62.

Hail F. and Pozo S. (2008), "Currency crisis contagion and the identification of transmission channels", International Review of Economics and Finance, 17 (4), pp. 572-588.

Hamilton J.D. (1989), "A new approach to the economic analysis of nonstationary time series and the business cycle", Econometrica, vol. 57, pp. 357-384.

Hamilton, J.D. and Susmel R. (1994), "Autoregressive conditional heteroscedasticity and changes in regime", Journal of Econometrics, 64, pp. 307-333.

Henry O. (2009), "Regime switching in the relationship between equity returns and short-term interest rates". Journal of Banking and Finance, 33, pp. 405-414.

Horta P., Mendes C. and Vieira I. (2008), "Contagion effects of the US subprime crisis on developed countries". CEFAGE-UE Working Paper 2008/08.

Ismail, M.T. and Isa, Z. (2008), "Identifying regime shifts in Malaysian stock market returns", International Research Journal of Finance and Economics, 15, pp. 44-57.

Ito T. and Portes R. (1998), "Dealing with Asian Financial Crises". European Economic Perspectives, 17, CERP, pp. 3-4.

Kamin S. B., Schindler J. W. and Samuel S. L. (2001). "The contribution of domestic and external factors to emerging market devaluation crises: An early warning systems approach". 
International Finance Discussion Paper, $\mathrm{n}^{\circ} 711$. Board of Governors of the Federal Reserve System.

Kaminsky G. and Reinhart C.M. (2000), "On crises, contagion and confusion". Journal of International Economics, 51, pp. 145-168.

Kaminsky G.L. and Reinhart C.M. (1999), "The Twin crises: The causes of Banking and Balance of Payments problems". The American Economic Review, 89 (3), pp. 473-500.

Khedhiri S. and Muhammad N. (2008), "Empirical analysis of the UAE stock market volatility", International Research Journal of Finance and Economics, 15, pp. 249-260..

Lagoarde-segot T., Lucey B.M., (2007), "International portfolio: is there a role for the Middle east and North Africa?", Journal of Multinational Financial Management, 17 (5), pp. 401410 .

Lagoarde-segot T., Lucey B.M. (2009), "Shift-contagion vulnerability in the MENA stock markets", The World Economy, 32(10), pp. 1478-1497.

Lahet D. (2009), "Le repositionnement des pays émergents: De la crise financière asiatique de 1997 à la crise de 2008”, Revue d'Economie Financière, 95, p. 275-306

Ljung, B. and Box G.E.P. (1978), "On a measure of lack of fit in time series models", Biometrika, 65 (2), pp. 297-303.

Marashdeh H. and Shrestha M.B. (2010), "Stock market integration in the GCC countries", International Research Journal of Finance and Economics, 37, pp. 103-114.

Mariano R., Gutlehin B., Ozmucun S., Sahabbir T. and Alper C.E. (2004). "Prediction of Currency crises: Case of Turkey". Review of Middle East Economics and Finance, 2(2), pp. 87-107.

Masson P. (1999), "Contagion: macroeconomic models with multiple equilibria". Journal of International Money and Finance, 18 (4), pp. 587-602.

Neaime, S. (2002), 'Liberalisation and Financial Integration of MENA Stock Markets', Paper presented at the 9th Economic Research Forum Meeting, American University in Sharjah, United Arab Emirates.

Reside J. R.E. and Gochoco-Bautista M.S. (1999), "Contagion and the Asian currency crisis". The Manchester School, 67 (5), Special Issue, pp. 460-474.

Rigobon R. (2003), "On the measurement of international propagation of shocks: is the transmission stable?". Journal of International Economics, 61(2), pp. 261-283.

Smimou K. and Karabegovic H. (2010), "On the relationship between economic freedom and equity returns in the emerging markets: Evidence from the Middle East and North Africa (MENA) stock markets", Emerging Markets Review, 11(2), pp. 119-151.

Soofi A. S. (2008), "Global financial integration and the MENA countries: Evidence from equity and money markets", Review of Middle East Economics and Finance, 4(2), pp. 1-24.

Valdes R.O. (1997), "Emerging Market Contagion: Evidence and Theory". Central Bank of Chile Working Papers, $\mathrm{n}^{\circ} 7$.

Van Rijckeghem C. and Weder B. (2001), "Source of contagion: is it finance or trade". Journal of International Economics, 54, pp. 293-308.

Van Rijckeghem C. and Weder B. (2003), "Spillovers through banking centers: a panel data analysis of bank flows". Journal of International Money and Finance, 22, pp. 483-509.

Yu J.-S. and Hassan M. K. (2006), "Global and regional integration of the Middle East and North Africa (MENA) stock markets", The Quarterly Review of Economics and Finance, 48(3), pp. 482-504. 


\section{Appendix 1}

Figure1: Daily price, returns and volatility of the MENA stock markets.
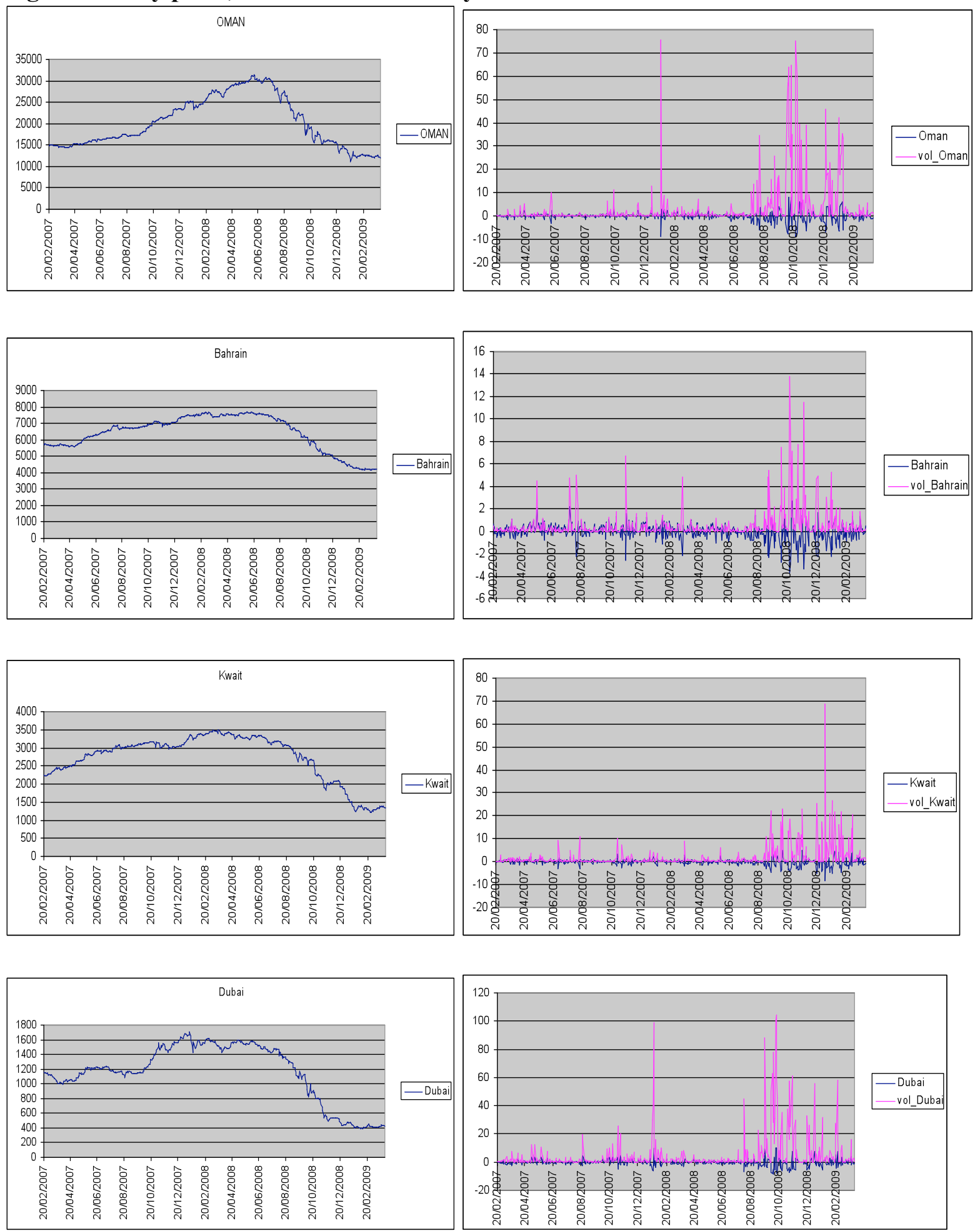

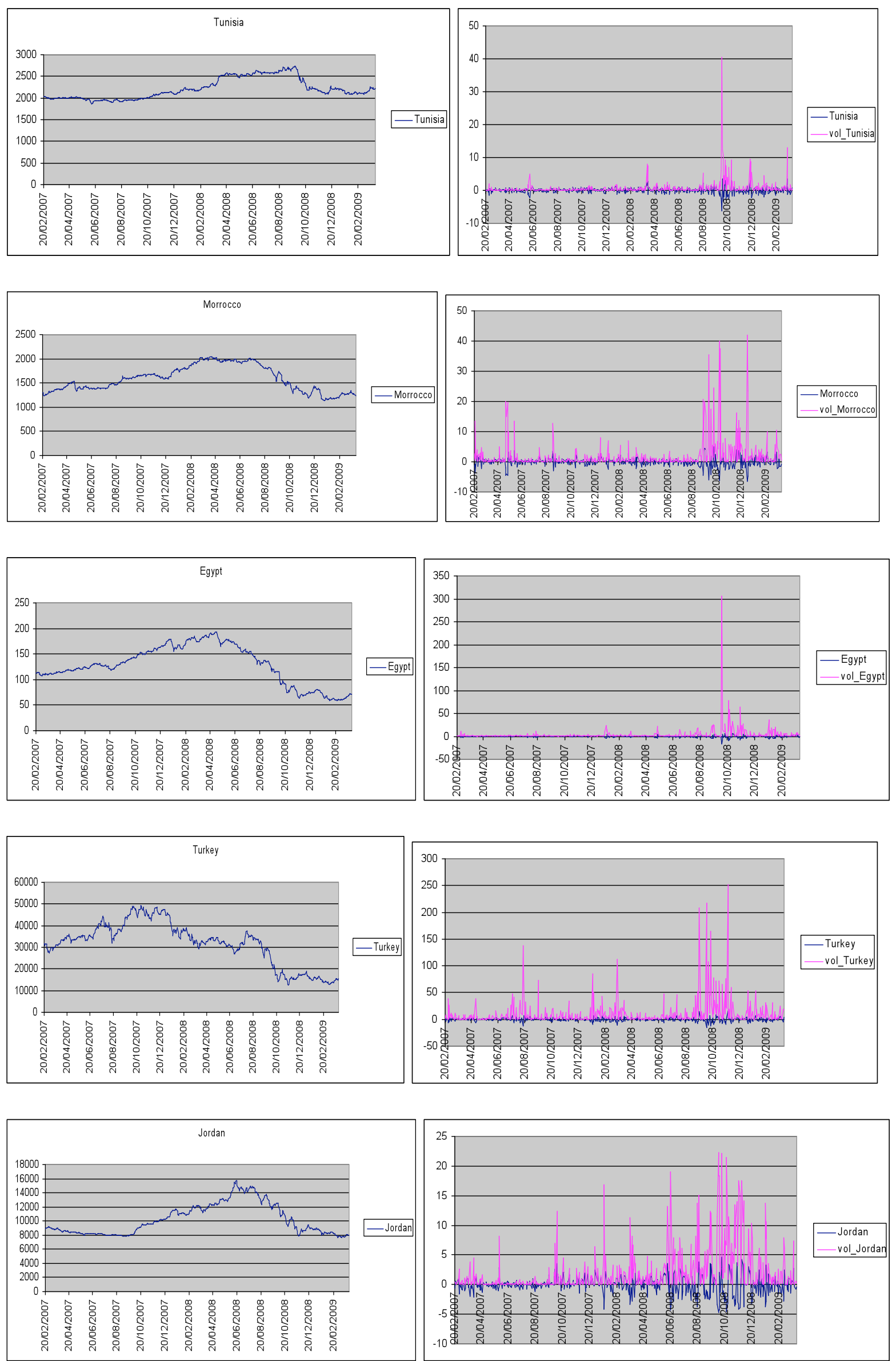

Figure2: Smoothed probabilities of regime 0 (crisis regime). 

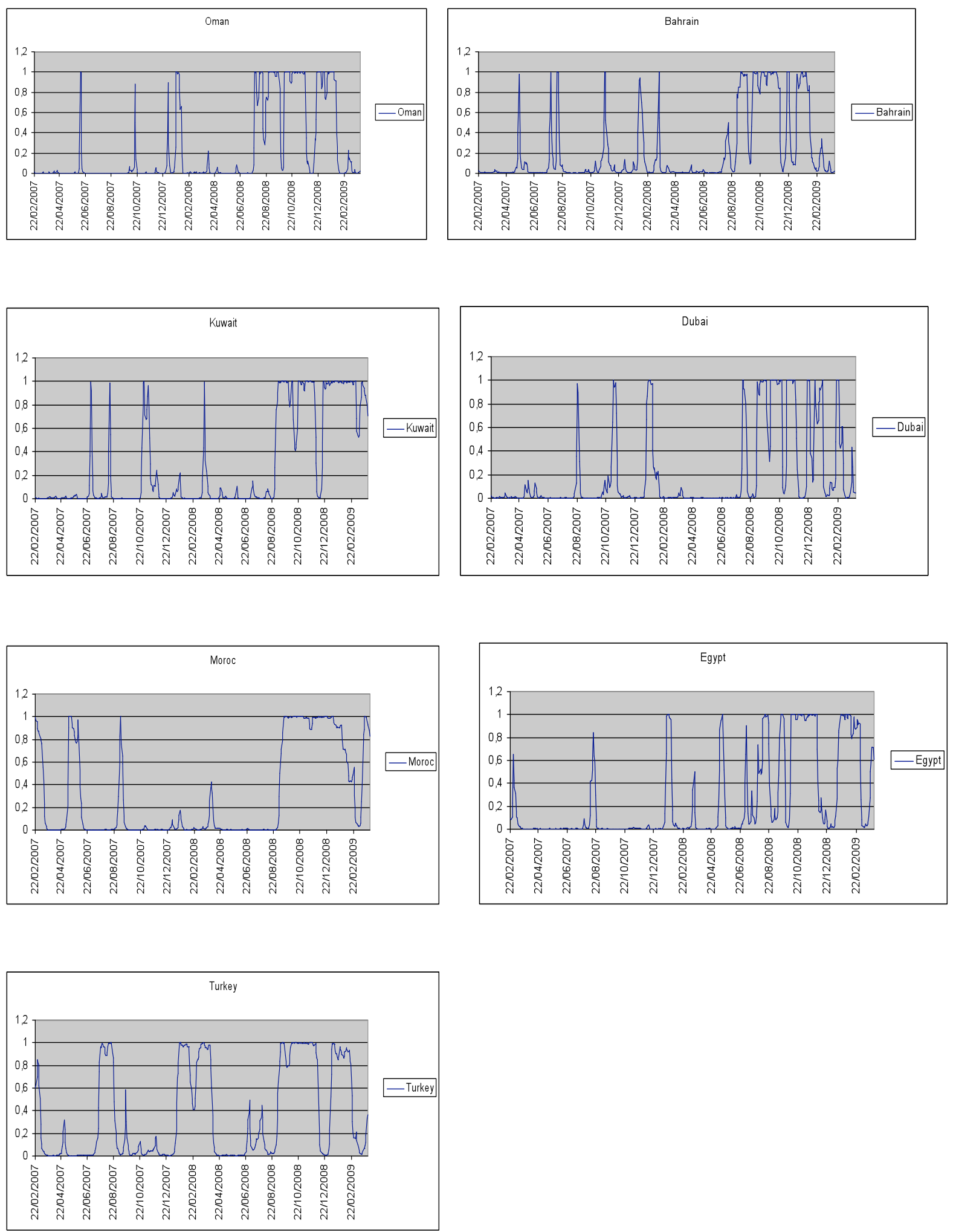
Table 1. Comparative indicators for MENA stock markets and other emerging markets (2007)

\begin{tabular}{|l|c|c|}
\hline Country & Listed stocks $^{\mathrm{a}}$ & ${\text { Liquidity }(\%)^{\mathrm{b}}}^{\mathrm{b}}$ \\
MENA markets & & \\
Oman & 125 & 22.6 \\
Bahrain & 51 & 4 \\
Kuwait & 196 & 100 \\
Dubai & 55 & 74.8 \\
Morocco & 73 & 29.8 \\
Egypt & 435 & 47.3 \\
Turkey & 319 & 129.7 \\
Jordan & 245 & 42.3 \\
& & \\
Emerging & & \\
Markets & & \\
Argentina & 111 & 8.87 \\
Mexico & 367 & 29.8 \\
Brazil & 404 & 57.08 \\
Korea & 1757 & 192.61 \\
Singapore & 762 & 77.6 \\
Philippines & 244 & 33.02 \\
Thailand & 523 & 66.6 \\
Malaysia & 986 & 57.07 \\
& & \\
\hline Sounce: Smia & & \\
\hline
\end{tabular}

Source: Smimou and Karabegovic (2010) for MENA markets. Lagoard-Segot and Lucey (2009) for Emerging markets.

a 'Listed companies' are the number of listed companies at the end of the year.

b 'Liquidity' corresponds to total value traded for the year divided by market capitalization.

Table 2: Average Daily Market Value Traded (US\$ bn)

\begin{tabular}{|l|r|r|r|r|r|r|}
\hline & \multicolumn{1}{|c|}{2005} & \multicolumn{1}{c|}{2006} & \multicolumn{1}{c|}{2007} & \multicolumn{1}{c|}{2008} & \multicolumn{1}{c|}{2009} & Change $^{(\mathrm{a})}$ \\
\hline Saudi Arabia & 4.415 & 5.611 & 2.728 & 2.094 & 1.300 & $-37.9 \%$ \\
\hline Kuwait & 0.402 & 0.244 & 0.558 & 0.534 & 0.150 & $-71.9 \%$ \\
\hline Qatar & 0.113 & 0.082 & 0.120 & 0.193 & 0.100 & $-48.1 \%$ \\
\hline Oman & 0.014 & 0.009 & 0.021 & 0.035 & 0.006 & $-82.8 \%$ \\
\hline UAE (DFM \& ADX) & 0.572 & 0.489 & 0.614 & 0.595 & 0.120 & $-79.8 \%$ \\
\hline Bahrain & 0.003 & 0.005 & 0.004 & 0.008 & 0.001 & $-88.1 \%$ \\
\hline Jordan & 0.090 & 0.700 & 0.600 & 0.100 & 0.040 & $-60.0 \%$ \\
\hline Egypt & 0.820 & 0.164 & 0.199 & 0.293 & 0.110 & $-62.5 \%$ \\
\hline
\end{tabular}

Source: Bloomberg, Zawya \& Dubai Abu Dhabi UAE Stocks and Shares Discussion Forum

(a) Change from December 2008 to January 19, 2009 
Table 3: Market Capitalization - Major MENA Markets (US\$ bn)

\begin{tabular}{|l|r|r|r|r|r|r|}
\hline & \multicolumn{1}{|c|}{2005} & \multicolumn{1}{|c|}{2006} & \multicolumn{1}{|c|}{2007} & \multicolumn{1}{c|}{2008} & 2009 & Change $^{\text {(a) }}$ \\
\hline Saudi Arabia & 646 & 327 & 519 & 247 & 239 & $-3.1 \%$ \\
\hline Kuwait & 142 & 144 & 211 & 121 & 99 & $-18.7 \%$ \\
\hline Qatar & 87 & 61 & 93 & 77 & 61 & $-21.1 \%$ \\
\hline Oman & 13 & 13 & 23 & 15 & 14 & $-8.7 \%$ \\
\hline UAE (DFM \& ADX) & 231 & 169 & 257 & 132 & 127 & $63.8 \%$ \\
\hline Bahrain & 17 & 21 & 27 & 20 & 19 & $-5 \%$ \\
\hline Jordan & 37 & 29 & 41 & 35 & 34 & $-1.9 \%$ \\
\hline Egypt & 81 & 95 & 137 & 57 & 57 & $0.7 \%$ \\
\hline
\end{tabular}

Source: Bloomberg, Zawya \& Global Research \& Dubai Abu Dhabi UAE Stocks and Shares Discussion Forum (a) Change from December 2008 to January 19, 2009

Table 4. Market capitalization to GDP ratio ${ }^{\text {(a) }}$

\begin{tabular}{|l|c|c|c|}
\hline Country & 2006 & 2007 & 2008 \\
\hline Bahrain & 133 & - & - \\
Egypt & 87 & 107 & 53 \\
Jordan & 200 & 249 & 179 \\
Lebanon & 37 & 44 & 34 \\
Morocco & 75 & 101 & 76 \\
Oman & 45 & - & - \\
Tunisia & 14 & 15 & 16 \\
Turkey & 31 & 44 & 15 \\
\hline
\end{tabular}

Source: Data extracted from the World Bank data base

(a) Market capitalization/GDP' is the market capitalization at the end of each year divided by GDP for the year 